\title{
Lysosome-targeted drug combination induces multiple organelle dysfunctions and non-canonical death in pancreatic cancer cells
}

\author{
SUMIRE SUZUKI*, MASATO OGAWA*, MASAYA MIYAZAKI, KOHKI OTA, HIROMI KAZAMA, \\ AYAKO HIROTA, NAOHARU TAKANO, MASAKI HIRAMOTO and KEISUKE MIYAZAWA \\ Department of Biochemistry, Tokyo Medical University, Tokyo 160-8402, Japan
}

Received August 13,2021; Accepted December 3, 2021

DOI: 10.3892/or.2021.8251

\begin{abstract}
Pancreatic cancer is one of the leading causes of cancer-related mortality and has the lowest 5-year survival rate. Therefore, novel strategies are urgently required to treat pancreatic cancer. Pancreatic ductal adenocarcinoma (PDAC) cells rely on enhanced lysosomal function for survival and proliferation to facilitate the degradation of contents accumulated via autophagy and macropinocytosis. Previously, we have reported that the combination of epidermal growth factor receptor/HER2 inhibitor lapatinib and sphingosine analog fingolimod (FTY720) confers a significant cytostatic effect in lung cancer cells. In the present study, the combined effects of these drugs on PDAC cell lines, BxPC-3, KP-4, PANC-1 and MIA PaCa-2, were examined. It was observed
\end{abstract}

Correspondence to: Dr Masaki Hiramoto, Department of Biochemistry, Tokyo Medical University, 6-1-1 Shinjuku, Shinjuku-ku, Tokyo 160-8402, Japan

E-mail: hiramoto@tokyo-med.ac.jp

${ }^{*}$ Contributed equally

Abbreviations: ACTB, $\beta$-actin; ANOVA, analysis of variance; CALR, calreticulin; $\mathrm{Ca}^{2+}$, calcium; CASP3, caspase-3; COX IV, cytochrome c oxidase subunit 4; CTSB, cathepsin B; DDIT3, DNA damage inducible transcript 3; DMSO, dimethyl sulfoxide; ER, endoplasmic reticulum; FTY720, fingolimod; GAPDH, glyceraldehyde-3-phosphate dehydrogenase; HBSS, Hanks' balanced salt solution; HCQ, hydroxychloroquine; IgG, immunoglobulin G; LAMP2, lysosome-associated membrane glycoprotein 2; LDH, lactate dehydrogenase; LGALS3, galectin-3; LMP, lysosomal membrane permeabilization; NSCLC, non-small cell lung cancer; PARP1, poly [ADP-ribose] polymerase 1; PDAC, pancreatic ductal adenocarcinoma; p-H2AX, phosphorylated-histone H2A.X; PI, propidium iodide; qPCR, quantitative polymerase chain reaction; TGOLN2, trans-Golgi network integral membrane protein 2; XBP1, $\mathrm{X}$-box-binding protein 1

Key words: lysosome-targeted drug combination, pancreatic cancer cells, lysosomal membrane permeabilization, endoplasmic reticulum stress, mitochondrial depolarization, non-canonical cell death, calcium homeostasis, lapatinib, fingolimod, abemaciclib, hydroxychloroquine that FTY720 enhanced the lapatinib-induced cytotoxic effect and caused non-canonical and lysosome-dependent death in PDAC cells. Lapatinib and FTY720 induced lysosomal swelling and inhibited lysosomal acidification. Combination treatment with lapatinib and FTY720 increased lysosomal membrane permeability, induced mitochondrial depolarization, induced endoplasmic reticulum stress and disturbed intracellular calcium homeostasis. Additionally, the cytotoxic effect of lapatinib was enhanced by hydroxychloroquine or the CDK4/6 inhibitor abemaciclib, both of which induce lysosomal dysfunction. Collectively, these results indicated that the lysosome-targeted drug combination induces multiple organelle dysfunction and exerts a marked cytotoxic effect in PDAC cells.

\section{Introduction}

The incidence of pancreatic cancer, primarily pancreatic ductal adenocarcinoma (PDAC), is continuing to grow globally (1-3). PDAC is a highly fatal disease with a 5-year survival rate of $\sim 10 \%$ (2). Notably, the higher mortality associated with PDAC is often attributed to the inability to detect its presence until advanced stages (4). In addition, resistance to chemotherapy, invasiveness of cancer cells, and the existence of a stromal barrier are factors contributing to the high mortality rate of PDAC (5). Combination chemotherapy, modified FOLFIRINOX (5-fluorouracil, leucovorin, irinotecan and oxaliplatin), or gemcitabine plus nab-paclitaxel is often used to treat patients with distant metastasis $(6,7)$. Notably, current chemotherapeutic strategies involve a combination of conventionally used antimitotic and genotoxic agents, which can moderately improve the survival rate; however, severe side effects and acquired cancer cell drug resistance contribute to poor clinical outcomes (8). Therefore, there is an urgent need to develop more efficacious and less toxic therapeutic strategies.

PDAC is a poorly vascularized tumor embedded within a thick desmoplastic stroma (5), which utilizes high levels of basal autophagy and macropinocytosis to support its metabolism and maintain tumor growth (9). Notably, KRAS is the most frequently mutated gene in PDAC, and autophagy and macropinocytosis are upregulated by mutant KRAS to assist PDAC survival (10-12). Autophagy is an intracellular catabolic pathway activated under nutrient-starved conditions to induce 
the bulk turnover of cytoplasmic contents, including proteins and organelles, via double-membrane autophagosomes (13). Reportedly, PDAC cells activate autophagy of pancreatic stellate cells, which comprise the PDAC tumor stroma, and utilize them for the survival and proliferation of PDAC cells (14). Macropinocytosis is another nutrient acquisition pathway that permits the internalization of extracellular fluid via large endocytic vesicles, termed macropinosomes (15). Both autophagosomes and macropinosomes fuse with lysosomes to digest their contents, and the acquired nutrients are used to maintain cellular homeostasis and tumor growth $(13,15,16)$. Therefore, functional lysosomes play a pivotal role in nutrient acquisition via autophagy and macropinocytosis $(16,17)$ and are promising targets for developing suitable therapeutic strategies for pancreatic cancer.

We have previously reported that fingolimod (FTY720), a sphingosine analog and Food and Drug Administration (FDA)-approved drug for multiple sclerosis, sensitizes non-small cell lung cancer (NSCLC) cells to molecular-targeted drugs, such as lapatinib and sorafenib, and induces cell cycle arrest (18). In addition, FTY720 can reportedly modulate autophagy. Although some studies have documented the induction of autophagy by FTY720 (19-22), others have reported autophagy suppression (23-27). In our previous study, we reported that FTY720 could inhibit lysosomal function and autophagic flux in NSCLC cells (18). Additionally, FTY720 has been reported to induce lysosomal membrane permeabilization (LMP) and non-apoptotic death in human glioma cells (28). In the present study, the effects of combination treatment with lapatinib and FTY720 on PDAC cells were evaluated and the molecular mechanisms underlying these effects were examined.

\section{Materials and methods}

Reagents. Lapatinib, FTY720, hydroxychloroquine (HCQ), U18666A and gefitinib were purchased from Cayman Chemical Company and dissolved in dimethyl sulfoxide (DMSO) at a concentration of $20 \mathrm{mM}$ to obtain stock solutions. Abemaciclib and z-VAD-FMK, pan-caspase inhibitors, were purchased from AdooQ BioScience. E64d and pepstatin A, inhibitors of lysosomal proteases, were purchased from Peptide Institute, Inc. Necrostatin-1, a specific inhibitor of receptor-interacting serine/threonine-protein kinase 1 (RIPK1), was purchased from Enzo Life Sciences, Inc., and N-acetyl-L-cysteine, staurosporine, bafilomycin $\mathrm{A}_{1}$ and Hanks' balanced salt solution (HBSS) were obtained from FUJIFILM Wako Pure Chemical Corporation. Hoechst 33342 was obtained from Nacalai Tesque, Inc., and DAPI was purchased from Sigma-Aldrich (Merck KGaA).

Antibodies. The following primary antibodies were used in the present study: Anti-caspase-3 (CASP3; cat. no. 9662), anti-cleaved CASP3 (cat. no. 9661), anti-poly [ADP-ribose] polymerase 1 (PARP1; cat. no. 9542), anti-histone H2A.X (H2AX; cat. no. 7631), anti-cathepsin B (CTSB; cat. no. 31718), anti-galectin-3 (LGALS3; cat. no. 87985), anti-cytochrome c oxidase subunit 4 (COX IV; cat. no. 11967), anti-calreticulin (CALR; cat. no. 12238), anti-HER2 (cat. no. 4290) and anti-phosphorylated (p)-HER2 (Tyr1221/1222; cat. no. 2243) were procured from Cell Signaling Technologies, Inc.; anti-lysosome-associated membrane protein 2 (LAMP2; cat. no. sc-18822), anti-glyceraldehyde-3-phosphate dehydrogenase (GAPDH; cat. no. sc-32233), anti- $\beta$-actin (ACTB; cat. no. sc-47778), anti-EGFR (cat. no. sc-03) and anti-p-EGFR (Tyr1173; cat. no. sc-101668) were from Santa Cruz Biotechnology, Inc.; anti-p-H2AX (Ser139; cat. no. 05-636) was from Merck KGaA; and anti-trans-Golgi network integral membrane protein 2 (TGOLN2/TGN46; cat. no. AHP500G) was purchased from Bio-Rad Laboratories, Inc.

Cell lines and culture conditions. Human PDAC cell lines BxPC-3 (KRAS wild-type), PANC-1 (KRAS G12D mutation) and MIA PaCa-2 (KRAS G12C mutation) were purchased from the American Type Culture Collection. The human embryonic cell line, 293, and HER2-positive breast cancer cell line, BT-474, were purchased from the American Type Culture Collection. KP-4 (KRAS G12D mutation), KP-3 (KRAS G12V mutation) and KP-2 (KRAS G12R mutation) were obtained from the Japanese Collection of Research Bioresources Cell Bank. The human bone marrow stromal cell line LP101 was a gift from Dr S. Aizawa (Nihon University School of Medicine, Tokyo, Japan) (29). All procured cell lines were cultured in RPMI-1640 medium (Sigma-Aldrich; Merck KGaA), supplemented with $10 \%$ heat-inactivated fetal bovine serum (Gibco; Thermo Fisher Scientific, Inc.) and $1 \%$ penicillin/streptomycin solution (FUJIFILM Wako Pure Chemical Corporation) at $37^{\circ} \mathrm{C}$ in a $5 \% \mathrm{CO}_{2}$ atmosphere.

Establishment of stable cell lines. To generate stable cell lines, PANC-1 cells were plated $\left(1 \times 10^{5}\right.$ cells/well) in a 24 -well plate for $24 \mathrm{~h}$. Cells were then transfected with plasmid DNA using Lipofectamine ${ }^{\circledR} 3000$ (Thermo Fisher Scientific, Inc.) according to the manufacturer's instructions. As previously described (30), the pEZ-F-X-box-binding protein 1 (XBP1)-Venus plasmid used in the present study was recombined with the pCAX-F-XBP1-Venus plasmid, a gift from Dr M. Miura (University of Tokyo, Tokyo, Japan) (31). After selecting transfected cells using puromycin $(2 \mu \mathrm{g} / \mathrm{ml})$, single clones of cells were isolated. The expression of XBP1-Venus fusion protein in response to $300 \mathrm{nM}$ thapsigargin (Nacalai Tesque, Inc.) was confirmed by examining fluorescence intensities derived from spliced XBP1-Venus using the IncuCyte ${ }^{\circledR}$ ZOOM cell imaging system (Essen Bioscience). After cloning and expansion, PANC-1/XBP1-Venus cells were cultured under the same conditions as PANC-1 cells, except for the addition of puromycin $(1 \mu \mathrm{g} / \mathrm{ml})$. PANC-1/green fluorescent protein (GFP)-LC3-red fluorescent protein (RFP)-LC3 $\Delta \mathrm{G}$ cells were established using the pMRX-IP-GFP-LC3-RFP-LC3 $\Delta \mathrm{G}$ plasmid, a gift from Dr N. Mizushima (University of Tokyo, Tokyo, Japan) (32), similar to PANC-1/XBP1-Venus cells.

Cell viability assay. The number of viable cells was assessed using the CellTiter-Blue Cell Viability Assay Kit (Promega Corporation), according to the manufacturer's instructions. Briefly, cells (BxPC-3, 8x10 3 cells/well; KP-4, 8x10 3 cells/well; PANC-1,6x10 3 cells/well; MIAPaCa-2,1.5x10 4 cells/well;KP-2, $8 \times 10^{3}$ cells/well; KP-3, $1.2 \times 10^{4}$ cells/well; $293,2 \times 10^{4}$ cells/well; LP101, 6x10 3 cells/well) were plated in 96-well flat-bottom culture plates and incubated with test reagents (lapatinib, FTY720, abemaciclib and HCQ, or a combination of these reagents) for 24 or $48 \mathrm{~h}$ at $37^{\circ} \mathrm{C}$ in a $5 \% \mathrm{CO}_{2}$ atmosphere. To 
determine the mode of cell death, BxPC-3 and KP-4 cells were incubated with the test reagents in the presence of $\mathrm{z}-\mathrm{VAD}-\mathrm{FMK}$ (25 or $50 \mu \mathrm{M})$, necrostatin-1 $(25 \mu \mathrm{M})$, N-acetyl-L-cysteine $(5 \mu \mathrm{M})$, or a combination of lysosome protease inhibitors E64d $(30 \mu \mathrm{M})$ and pepstatin $\mathrm{A}(15 \mu \mathrm{M})$ at $37^{\circ} \mathrm{C}$ for 24 or $48 \mathrm{~h}$. As a positive control for the induction of apoptosis, staurosporine $(0.3,1$ or $3 \mu \mathrm{M})$ was added to BxPC-3 cells and KP-4 cells, and the cells were cultured at $37^{\circ} \mathrm{C}$ for 24 or $48 \mathrm{~h}$. As a positive control for the induction of necroptosis (33), gefitinib ( 25 or $50 \mu \mathrm{M}$ ) was added to BxPC-3 cells and KP-4 cells under amino acid starvation conditions using Dulbecco's modified Eagle's medium without amino acid (FUJIFILM Wako Pure Chemical Corporation), and the cells were cultured at $37^{\circ} \mathrm{C}$ for 24 or $48 \mathrm{~h}$. Then, $1 \mathrm{~h}$ after the addition of the CellTiter-Blue reagent, fluorescence (560 $\mathrm{nm}$ excitation, $590 \mathrm{~nm}$ emission) was measured using a POWERSCAN HT 96-well plate reader (BioTek Instruments, Inc.). These experiments were performed multiple times (at least twice) on different days. The means and standard deviations presented in the graphs are from two independent experiments performed in triplicate.

Lactate dehydrogenase $(\mathrm{LDH})$ release assay. Cytotoxicity was assessed using the LDH Assay Kit-WST (Dojindo Laboratories, Inc.). Briefly, cells (BxPC-3, 8x10 ${ }^{3}$ cells/well; $\mathrm{KP}-4,8 \times 10^{3}$ cells/well; PANC-1, 6x $10^{3}$ cells/well; MIA PaCa-2, $1.5 \times 10^{4}$ cells/well) were plated in 96-well flat-bottom culture plates and incubated with test reagents (lapatinib, FTY720 and abemaciclib, or combination of these reagents) for 24 or $48 \mathrm{~h}$ at $37^{\circ} \mathrm{C}$ in a $5 \% \mathrm{CO}_{2}$ atmosphere. Then, cell lysis buffer was added to half of the wells to release intracellular LDH into the culture medium. After $30 \mathrm{~min}$, the developing solution was added to all wells, and the absorbance was measured at $490 \mathrm{~nm}$ using a SpectraMax iD3 microplate reader (Molecular Devices, LLC). The rate of cell death was calculated from the fluorescence ratio of wells, with and without the cell lysis buffer. These experiments were performed multiple times (at least twice) on different days. The means and standard deviations presented in graphs are from two independent experiments performed in triplicate.

Annexin V-propidium iodide (PI) staining. Cell death (early apoptotic, late apoptotic and necroptotic cell death) was assessed using the Annexin V-FITC Apoptosis Detection Kit (Nacalai Tesque, Inc.), according to the manufacturer's instructions. Briefly, cells (BxPC-3, KP-4 and PANC-1) treated with lapatinib $(10 \mu \mathrm{M})$, FTY720 $(5,10$ or $15 \mu \mathrm{M})$ or both at $37^{\circ} \mathrm{C}$ for $24 \mathrm{~h}$ were suspended in Annexin $\mathrm{V}$ binding buffer $\left(1 \times 10^{6}\right.$ cells $\left./ \mathrm{ml}\right)$, and stained with Annexin V-FITC and PI for $15 \mathrm{~min}$ at room temperature in the dark. After washing, cells were analyzed by flow cytometry using an Attune ${ }^{\mathrm{TM}}$ Acoustic Focusing Cytometer (Thermo Fisher Scientific, Inc.). Data analysis was performed using the Attune Cytometric software v2.1 (Thermo Fisher Scientific, Inc.).

May-Grünwald-Giemsa staining. Briefly, cells (BxPC-3,

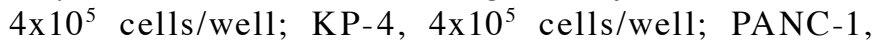
$3 \times 10^{5}$ cells/well) were seeded and cultured for $24 \mathrm{~h}$ in $60 \mathrm{~mm}$-dishes, followed by treatment with lapatinib $(10 \mu \mathrm{M})$ and FTY720 $(10$ or $15 \mu \mathrm{M})$ at $37^{\circ} \mathrm{C}$ for $24 \mathrm{~h}$. To detect adherent and detached cells, floating cells in culture medium and trypsin-treated adherent cells were collected. Then, cells were spread onto glass slides using a Cytospin 4 centrifuge (Thermo Fisher Scientific, Inc.) and air-dried. These cells were stained with May-Grünwald's stain solution (Muto Pure Chemicals Co., Ltd.) for $3 \mathrm{~min}$ at room temperature. The glass slides were allowed to stand for another 3 min after adding the same phosphate-buffered saline (PBS) volume. After removing the May-Grünwald's stain solution, the cells were stained with diluted (1:20 with water) Giemsa's stain solution (Muto Pure Chemicals Co., Ltd.) for $20 \mathrm{~min}$ at room temperature. After washing and drying, the cells were observed using a BZ-X810 digital light microscope (Keyence Corporation) featuring PlanApo 60x NA1.40 (Nikon Corporation).

Immunoblotting. Total proteins were extracted from cells (BxPC-3, KP-4, PANC-1, MIA PaCa-2 and BT-474) with lysis buffer containing $50 \mathrm{mM}$ Tris- $\mathrm{HCl}$ (pH 8.0), $150 \mathrm{mM}$ $\mathrm{NaCl}, 1.0 \%$ NonidetP-40, $0.5 \%$ sodium deoxycholate, $0.1 \%$ sodium dodecyl sulfate (SDS) and a protease inhibitor cocktail (Nacalai Tesque, Inc.). Each sample was sonicated continuously on ice for 20 pulses $(0.5 \mathrm{sec}$ on/off) to solubilize aggregated proteins using a Branson 450D Sonifier (Emerson Electric Co.). Protein concentrations were determined using a bicinchoninic acid protein assay kit (Pierce; Thermo Fisher Scientific, Inc.). Cellular proteins $(10 \mu \mathrm{g})$ were resolved via SDS-PAGE (5-20\% gradient gel) and subsequently transferred onto Immobilon-P membranes (MilliporeSigma). The membranes were blocked with 5\% non-fat milk for $1 \mathrm{~h}$ at room temperature and probed with primary antibodies at $4^{\circ} \mathrm{C}$ overnight. The primary antibodies used for immunoblotting were as follows: Anti-CASP3 (1:1,000), anti-cleaved CASP3 $(1: 1,000)$, anti-PARP1 (1:1,000), anti-p-H2AX $(1: 2,000)$, antiH2AX (1:1,000), anti-CTSB (1:1,000), anti-GAPDH $(1: 1,000)$ and anti-ACTB $(1: 1,000)$. The membranes were incubated with horseradish peroxidase-conjugated secondary antibodies [anti-mouse immunoglobulin G (IgG; cat. no. 115-035-003; 1:20,000) or anti-rabbit IgG (cat. no. 711-035-152; 1:20,000); both from Jackson ImmunoResearch Laboratories, Inc.] for $1 \mathrm{~h}$ at room temperature. Immunoreactive proteins were detected using an enhanced chemiluminescence reagent (Immobilon Western Chemiluminescent HRP Substrate; MilliporeSigma). Densitometry was performed using the WSE-6300 Luminograph III molecular imager (ATTO Corporation) and ATTO CS Analyzer 4 densitograph software (version 2.3.1, ATTO Corporation).

Immunofluorescence analysis. Briefly, BxPC-3 $\left(3 \times 10^{4}\right.$ cells/well $)$ and KP-4 $\left(2 \times 10^{4}\right.$ cells/well $)$ cells were seeded onto cover glasses in 24-well plates for $24 \mathrm{~h}$. Cells were then treated with either lapatinib $(10 \mu \mathrm{M})$, FTY720 (5 or $10 \mu \mathrm{M}$ ) or both at $37^{\circ} \mathrm{C}$ for 4,10 or $24 \mathrm{~h}$. Cells on cover glasses were washed twice with PBS, fixed in $2 \%$ paraformaldehyde for $10 \mathrm{~min}$ at room temperature, and then permeabilized by incubation with $0.1 \%$ Triton X-100 for $5 \mathrm{~min}$ (room temperature). For staining with LAMP2 antibody, cells on cover glasses were washed twice with PBS and fixed in $2 \%$ methanol for $15 \mathrm{~min}$ at $-30^{\circ} \mathrm{C}$. The cover glasses were then blocked with $10 \%$ newborn calf serum (Gibco; Thermo Fisher Scientific, Inc.) for $1 \mathrm{~h}$ at room temperature, followed by incubation with a primary antibody at $4^{\circ} \mathrm{C}$ overnight. The 
primary antibodies used for immunofluorescence analysis were as follows: Anti-LAMP2 (1:100), anti-LGALS3 (1:200), anti-COX IV (1:200), anti-CALR (1:400) and anti-TGOLN2 (1:400). After washing three times, cover glasses were incubated with Alexa Fluor 488-conjugated anti-Rabbit IgG (cat. no. A-11034; 1:1,000) and/or Alexa Fluor 555-conjugated anti-Mouse IgG (cat. no. A-21424; 1:1,000) (Molecular Probes; Thermo Fisher Scientific, Inc.) at $37^{\circ} \mathrm{C}$ for $1 \mathrm{~h}$. Next, the cover glasses were washed three times and mounted in ProLong Diamond Antifade Mountant (Thermo Fisher Scientific, Inc.). Cells were visualized using an LSM 700 confocal laser scanning fluorescence microscope (Zeiss $\mathrm{GmbH}$ ) equipped with a Plan-Apochromat 63x/1.4 oil DIC (Zeiss GmbH). All images were acquired and processed using the ZEN 2012 software (version 8.1.0.484; Zeiss $\mathrm{GmbH}$ ). Object-based fluorescence intensity, lysosome size and colocalization of fluorescence signals were measured using ImageJ software (1.50i; National Institutes of Health). Images used to compare different treatments were acquired with the same instrument settings and exposure times and were processed equally. The results are presented in graphs for the DMSO-treated sample as 1 . In experiments with glass bottoms (immunofluorescence analysis, LysoTracker staining, JC-1 staining and Fluo-8-AM staining), FTY720 was used at $5 \mu \mathrm{M}$ for combination treatment with $10 \mu \mathrm{M}$ lapatinib, as PDAC cells are easily detached from the glass bottom following combination treatment with $10 \mu \mathrm{M}$ FTY720 and $10 \mu \mathrm{M}$ lapatinib.

LysoTracker staining to assess lysosomal function. Briefly, cells (BxPC-3, 3x10 4 cells/well and KP-4, 2x10 4 cells/well) were seeded into CELLview 35-mm glass-bottom cell culture dishes with four compartments (cat. no. 627870; Greiner Bio-One International $\mathrm{GmbH}$ ) for $24 \mathrm{~h}$. Cells were then treated with either lapatinib $(10 \mu \mathrm{M})$, FTY720 $(5$ or $10 \mu \mathrm{M})$ or both at $37^{\circ} \mathrm{C}$ for 1, 2, 4 or $10 \mathrm{~h}$. LysoTracker Red DND-99 (50 nM; Molecular Probes; Thermo Fisher Scientific, Inc.) was added during the last $1 \mathrm{~h}$ at $37^{\circ} \mathrm{C}$. Next, cells were visualized using an LSM 700 confocal laser scanning fluorescence microscope (Zeiss $\mathrm{GmbH}$ ) equipped with a Plan-Apochromat 63x/1.4 oil DIC (Zeiss GmbH). All images were acquired and processed using ZEN 2012. The object-based fluorescence intensity was measured using Image J software.

JC-1 staining to assess mitochondrial function. Briefly, cells (BxPC-3, 3x10 4 cells/well and KP-4, 2x10 4 cells/well) were seeded into CELLview 35-mm glass-bottom cell culture dishes with four compartments for $24 \mathrm{~h}$. These cells were treated with a combination of lapatinib $(10 \mu \mathrm{M})$ and FTY720 $(5 \mu \mathrm{M})$ at $37^{\circ} \mathrm{C}$ for 1 or $4 \mathrm{~h}$. JC-1 dye $(5 \mu \mathrm{M}$; FUJIFILM Wako Pure Chemical Corporation) was added during the last $30 \mathrm{~min}$ at $37^{\circ} \mathrm{C}$. Next, the cells were visualized using an LSM 700 confocal laser scanning fluorescence microscope (Zeiss $\mathrm{GmbH}$ ) equipped with a Plan-Apochromat 63x/1.4 oil DIC (Zeiss $\mathrm{GmbH})$. All images were acquired and processed using ZEN 2012. The object-based fluorescence intensity was measured using ImageJ software.

Fluo-8-AM staining to assess intracellular calcium $\left(\mathrm{Ca}^{2+}\right)$ concentrations. Briefly, cells (BxPC-3, 3x10 4 cells/well and KP-4, $2 \times 10^{4}$ cells/well) were seeded into CELLview 35-mm glass-bottom cell culture dishes with four compartments. Then, 2 days after seeding, the culture medium was replaced with fresh medium containing $5 \mu \mathrm{M}$ Fluo-8-AM (AAT Bioquest, Inc.) and cultured at $37^{\circ} \mathrm{C}$ for $1 \mathrm{~h}$. After washing, the cells were treated with a combination of lapatinib $(10 \mu \mathrm{M})$ and FTY720 $(5 \mu \mathrm{M})$ at $37^{\circ} \mathrm{C}$ for $1 \mathrm{~h}$. Cells were then visualized using an LSM 700 confocal laser scanning fluorescence microscope (Zeiss $\mathrm{GmbH}$ ) equipped with a Plan-Apochromat 40x/1.4 oil DIC (Zeiss GmbH). All images were acquired and processed using ZEN 2012. The object-based fluorescence intensity was measured using ImageJ software.

Gene expression analysis. Total RNA was extracted from BxPC-3, KP-4, PANC-1 and MIA PaCa-2 cells using the NucleoSpin RNA kit (Takara Bio, Inc.). The RNA was reverse transcribed to cDNA using PrimeScript RT Master Mix (Takara Bio, Inc.) at $37^{\circ} \mathrm{C}$ for $15 \mathrm{~min}$. The expression of endoplasmic reticulum (ER) stress-associated gene, DNA damage-inducible transcript 3 (DDIT3/CHOP), was determined by quantitative polymerase chain reaction (qPCR) using SYBR Premix Ex Taq II Tli RNase H Plus (Takara Bio, Inc.). The primer sequences employed were as follows: 5'-AAATCAGAGCTG GAACCTGAGGA-3' and 5'-CCATCTCTGCAGTTGGAT CAGTC-3' for DDIT3; 5'-GCACCGTCAAGGCTGAGAAC-3' and 5'-TGGTGAAGACGCCAGTGGA-3' for GAPDH. qPCR was performed using Thermal Cycler Dice Real-Time System TP800 (Takara Bio, Inc.) under the following conditions: Initial denaturation at $95^{\circ} \mathrm{C}$ for $30 \mathrm{sec}$, followed by 40 cycles of denaturation at $95^{\circ} \mathrm{C}$ for $5 \mathrm{sec}$, and annealing and extension at $60^{\circ} \mathrm{C}$ for $30 \mathrm{sec}$. Data were analyzed using Thermal Cycler Dice Real-Time System Software (Takara Bio, Inc.) and standardized to GAPDH as an internal control. The comparative $\mathrm{Cq}$ method $\left(2^{-\Delta \Delta \mathrm{Cq}}\right)$ was used for the relative quantification of gene expression (34).

Assessment of ER stress using the spliced XBPI-Venus system. PANC-1/XBP1-Venus cells $\left(1 \times 10^{4}\right.$ cells/well) were plated in a 96 -well plate $24 \mathrm{~h}$ prior to treatment. Fluorescence intensities derived from spliced XBP1-Venus were monitored during the $24 \mathrm{~h}$-culture under various conditions, using an IncuCyte ZOOM cell imaging system (Essen Bioscience). Cell confluency in each imaging field was monitored by simultaneously capturing phase-contrast images using IncuCyte ZOOM. In addition, ER stress was measured as alterations in the Venus fluorescence intensity per cell confluency.

Assessment of autophagic flux using GFP-LC3-RFP-LC3 $\triangle G$ system. Prior to treatment, PANC-1/GFP-LC3-RFP-LC3 $\Delta \mathrm{G}$ cells $\left(9 \times 10^{3}\right.$ cells/well) were plated in a 96 -well plate for $24 \mathrm{~h}$. Fluorescence intensities derived from GFP-LC3 and RFP-LC3 $\Delta \mathrm{G}$ were monitored during the $24 \mathrm{~h}$-culture at $37^{\circ} \mathrm{C}$ with $5 \% \mathrm{CO}_{2}$ using IncuCyte ZOOM. The cells were treated with lapatinib $(10$ or $20 \mu \mathrm{M})$ or FTY720 $(10$ or $20 \mu \mathrm{M})$ at $37^{\circ} \mathrm{C}$ for $24 \mathrm{~h}$ in 96 -well plates in quadruplicate. As a positive control for the induction of autophagic flux, the cells were cultured under starvation conditions using $\mathrm{HBSS}$ at $37^{\circ} \mathrm{C}$ for $24 \mathrm{~h}$. As a positive control for the suppression of autophagic flux, the cells were treated with bafilomycin $A_{1}(10 \mathrm{nM})$ at $37^{\circ} \mathrm{C}$ for $24 \mathrm{~h}$. Autophagic flux was presented as alterations 
in the relative intensities of GFP/RFP, calculated from the measured fluorescence intensities of GFP and RFP.

Assessment of cell death. Cells (BxPC-3, 8x10 cells/well; $\mathrm{KP}-4,8 \times 10^{3}$ cells/well; PANC-1, 6x10 3 cells/well) were plated in 96-well flat-bottom culture plates and pretreated with $\mathrm{U} 18666 \mathrm{~A}(0.1,0.3,1$ or $3 \mu \mathrm{M})$ at $37^{\circ} \mathrm{C}$ for $24 \mathrm{~h}$. Cells were then treated with a combination of lapatinib $(10 \mu \mathrm{M})$ and FTY720 (10 or $15 \mu \mathrm{M})$ in the presence of PI $(2.5 \mu \mathrm{g} / \mathrm{ml}$; Sigma-Aldrich; Merck $\mathrm{KGaA}$ ) at $37^{\circ} \mathrm{C}$ for 24 or $48 \mathrm{~h}$. Cell death was assessed by counting the number of PI-stained red fluorescent signals using IncuCyte ZOOM.

DNA fragmentation assay. Extraction and separation of fragmented DNA were performed as previously described (35). Briefly, cells (BxPC-3, 4x10 cells/well; KP-4, 4x10 cells/well; MIA PaCa-2, $7.5 \times 10^{5}$ cells/well) were seeded and cultured for $24 \mathrm{~h}$ in $60 \mathrm{~mm}$-dishes. Cells were then treated with a combination of lapatinib $(10 \mu \mathrm{M})$ and FTY720 $(10 \mu \mathrm{M})$ at $37^{\circ} \mathrm{C}$ for $24 \mathrm{~h}$ and lysed in a buffer containing $10 \mathrm{mM}$ Tris- $\mathrm{HCl}(\mathrm{pH} 8.0)$, $1 \mathrm{mM}$ EDTA and $0.5 \%$ Triton X-100. The lysate was centrifuged at $15,000 \mathrm{x} \mathrm{g}$ for $15 \mathrm{~min}$ at $4^{\circ} \mathrm{C}$ to separate fragmented DNA in the supernatant from intact chromatin in the pellet. DNA in the supernatant was treated with RNase A at $37^{\circ} \mathrm{C}$ for $1 \mathrm{~h}$, followed by proteinase $\mathrm{K}$ at $50^{\circ} \mathrm{C}$ for $2 \mathrm{~h}$. DNA was purified using silica-based spin columns, NucleoSpin ${ }^{\circledR}$ Gel and PCR Clean-up (Takara Bio, Inc.) and separated by electrophoresis on a $2 \%$ agarose gel with the DNA fluorescence dye, Midori Green Direct (Nippon Gene Co., Ltd.). Then, DNA was visualized using an LED illuminator (Fas-Digi; Nippon Gene Co., Ltd.).

Filipin III staining to assess cholesterol accumulation. Briefly, KP-4 cells $\left(2 \times 10^{4}\right.$ cells/well) were seeded into CELLview $35-\mathrm{mm}$ glass-bottom cell culture dishes with four compartments for $24 \mathrm{~h}$, and the cells were treated in the presence $(1 \mu \mathrm{M})$ or absence of U18666A at $37^{\circ} \mathrm{C}$ for $24 \mathrm{~h}$. Next, cells were washed with PBS and fixed with $3 \%$ paraformaldehyde for $1 \mathrm{~h}$ at room temperature, followed by incubation with $20 \mathrm{mM}$ glycine for $10 \mathrm{~min}$ to quench the paraformaldehyde. For cholesterol staining, the cells were incubated with $25 \mu \mathrm{g} / \mathrm{ml}$ filipin III (Santa Cruz Biotechnology, Inc.) for $2 \mathrm{~h}$ at room temperature. After washing with PBS, the cells were observed using a BZ-X810 digital microscope (Keyence Corporation) featuring PlanApo 60x NA1.40 (Nikon Corporation).

Statistical analysis. Data are presented as the mean \pm standard deviation or median with interquartile ranges. All data presented in the graphs are from at least two independent experiments. Statistical analyses were performed by using parametric, unpaired two-tailed Student's t-test and analysis of variance (ANOVA), or non-parametric, Mann Whitney U test and Kruskal-Wallis test, methods where appropriate. The Student's t-test and Mann Whitney U test were performed using Microsoft Excel version 16.51 (Microsoft Corporation) with the add-in software, Excel Statistical Program File ystat2008 (Igakutosho-shuppan Ltd.). One-way ANOVA followed by Tukey's post hoc test, two-way ANOVA followed by Bonferroni's post hoc test, and Kruskal-Wallis with Dunn's post hoc test were performed using SPSS software version 28
Table $\mathrm{I} \mathrm{IC}_{50}$ and combination index values of lapatinib and FTY720.

\begin{tabular}{lccc}
\hline Cell lines & $\begin{array}{c}\mathrm{IC}_{50} \text { for } \\
\text { lapatinib, } \mu \mathrm{M}\end{array}$ & $\begin{array}{c}\mathrm{IC}_{50} \text { for } \\
\mathrm{FTY720,} \mathrm{M}\end{array}$ & $\begin{array}{c}\text { Combination } \\
\text { index }\end{array}$ \\
\hline BxPC-3 & 15.0 & 8.6 & 0.69 \\
KP-4 & 18.9 & 10.3 & 0.98 \\
PANC-1 & $>40.0$ & 18.2 & $\mathrm{ND}$ \\
MIA PaCa-2 & 15.1 & 17.9 & 0.79 \\
KP-2 & 31.0 & 18.0 & 0.70 \\
KP-3 & $>40.0$ & 21.8 & ND \\
293 & 18.3 & 8.6 & ND \\
LP101 & 12.3 & 14.4 & 1.11 \\
\hline
\end{tabular}

$\mathrm{IC}_{50}$ values were determined from the relative cell growth inhibition at $48 \mathrm{~h}$. Combination index values were calculated from the relative cell growth inhibition at $48 \mathrm{~h}$ with lapatinib $(10 \mu \mathrm{M})$ and FTY720 $(10 \mu \mathrm{M})$. Combination index values in PANC-1, KP-3 and 293 cells could not be determined. $\mathrm{IC}_{50}$, half-maximal inhibition concentration; $\mathrm{ND}$, not determined.

(IBM Corp.). $\mathrm{P}<0.05$ was considered to indicate a statistically significant difference.

\section{Results}

Combination treatment with lapatinib and FTY720 enhances growth inhibition in PDAC cells. Previously, we reported that combination treatment with FTY720 and the EGFR/HER2 inhibitor lapatinib or multikinase inhibitor sorafenib can show prominent growth inhibitory activity in NSCLC cells (18). In the present study, we focused on lysosomotropic drugs (36). Accordingly, PDAC cells, including BxPC-3, KP-4, PANC-1, MIA PaCa-2, KP-3 and KP-2, were treated with lapatinib, FTY720 or a combination of these drugs. It was observed that the growth inhibitory effect of lapatinib was significantly enhanced following combination treatment with FTY720 in all cell lines (Figs. 1 and S1-S3). Table I presents the values of the half-maximal inhibition concentration $\left(\mathrm{IC}_{50}\right)$ and combination index (CI) of lapatinib and FTY720. Specifically, CI $<1$, $\mathrm{CI}=1$ and $\mathrm{CI}>1$ indicate synergistic, additive and antagonistic effects, respectively (37). It was noted that FTY720 synergistically enhanced the growth inhibitory effect of lapatinib in BxPC-3, MIA PaCa-2 and KP-2 cells. The combined effect of these two drugs was nearly additive in KP-4 cells and antagonistic in the non-cancerous cell line LP101.

One of the biological effects of FTY720 can be attributed to its phosphorylated form, FTY720-P, which strongly binds to sphingosine 1-phosphate receptor 1 (S1PR1), inducing the internalization and degradation of S1PR1 at submicromolar concentrations $(38,39)$. However, in the current study, the growth inhibitory effect of FTY720 on PDAC cells was observed only at micromolar concentrations (Fig. S1). Therefore, FTY720-mediated growth inhibition in PDAC cells was not attributed to its phosphorylated form, FTY720-P. Additionally, the major effect of lapatinib is typically attributed to the inhibition of EGFR and HER2 phosphorylation (40). However, the 

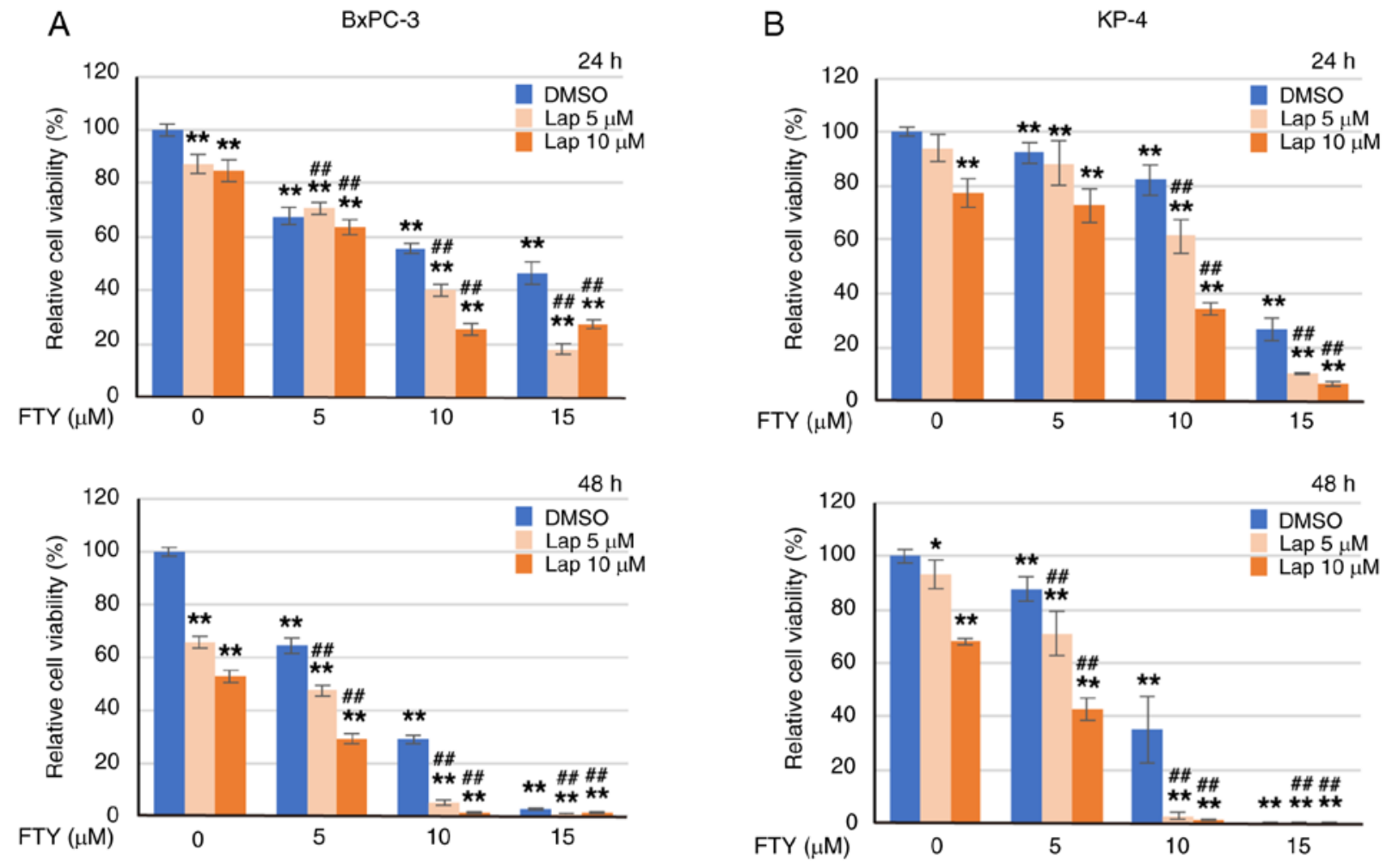

C

PANC-1

D

MIA PaCa-2
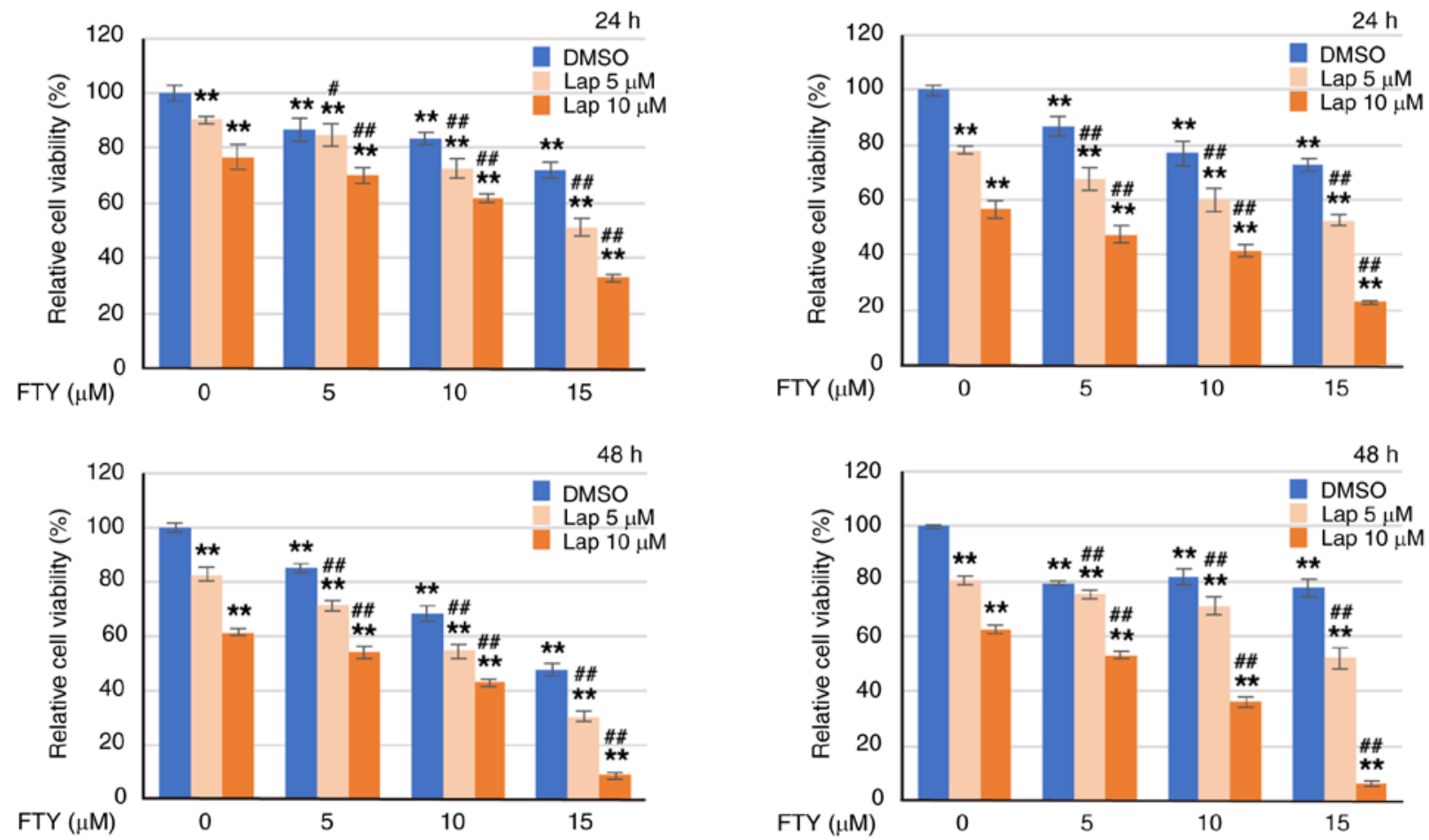

Figure 1. Inhibition of cell growth in pancreatic ductal adenocarcinoma cells. Cell viability was assessed at 24 and $48 \mathrm{~h}$ following treatment with indicated drugs in (A) BxPC-3, (B) KP-4, (C) PANC-1 and (D) MIA PaCa-2 cells. Data were analyzed using one-way ANOVA followed by Tukey's post hoc test. Data are presented as the mean \pm standard deviation, $\mathrm{n}=6$. ${ }^{*} \mathrm{P}<0.05$ and ${ }^{* * *} \mathrm{P}<0.01$ vs. FTY $0 \mu \mathrm{M} / \mathrm{Lap} 0 \mu \mathrm{M}$. ${ }^{\#} \mathrm{P}<0.05$ and ${ }^{\# \prime} \mathrm{P}<0.01$ vs. each respective FTY $0 \mu \mathrm{M}$. Lap, lapatinib; FTY, FTY720; DMSO, dimethyl sulfoxide.

expression of p-EGFR and p-HER2 was scarcely detected in PDAC cells (Fig. S4). Therefore, lapatinib-mediated cytostatic effects in PDAC cells were not attributed to the inhibition of EGFR/HER2 signaling.
In the present study, lapatinib was used at $10 \mu \mathrm{M}$, which was less than the $\mathrm{IC}_{50}$ value, and FTY720 was primarily used at a 10 or $15 \mu \mathrm{M}$ concentration, at which the two reagents acted synergistically. However, in experiments with glass bottoms, 
A

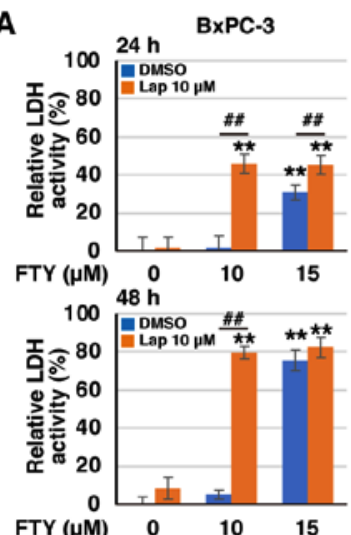

B
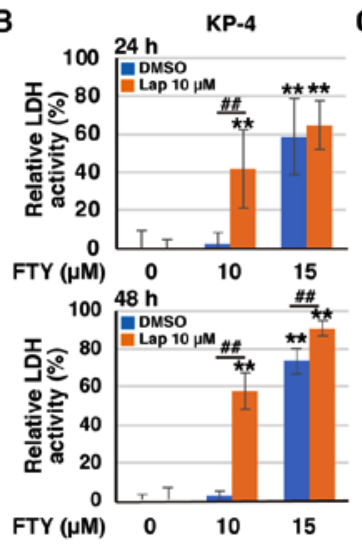

C
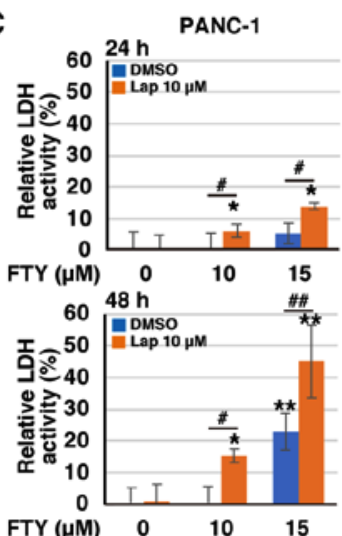

D

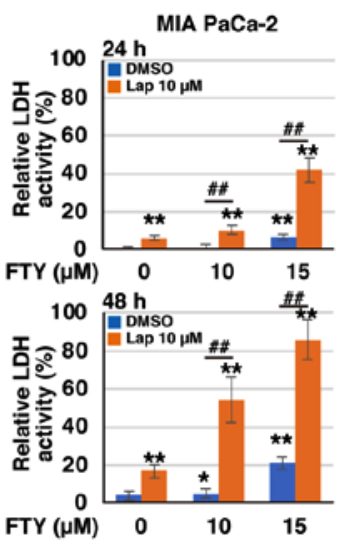

XP-4

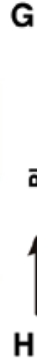

G
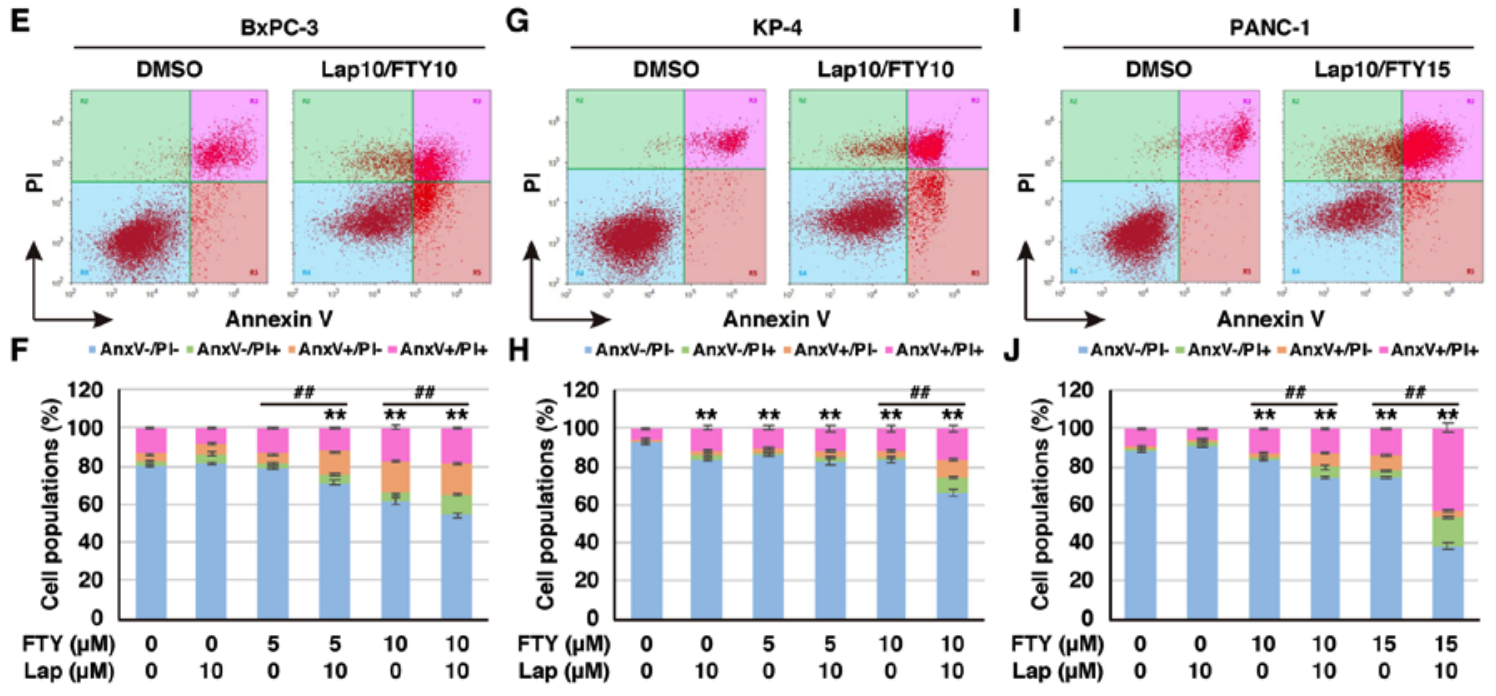

K

$\mathbf{L}$

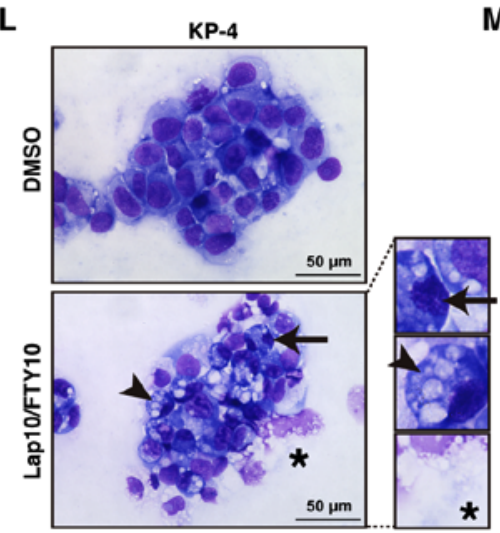

M

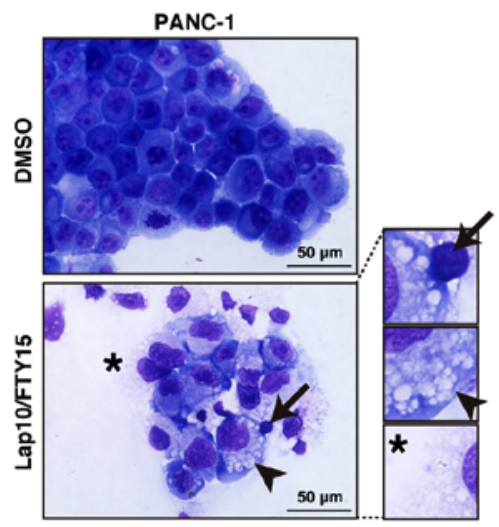

Figure 2. Induction of pancreatic ductal adenocarcinoma cell death. (A-D) Cytotoxicity was assessed at 24 and $48 \mathrm{~h}$ following treatment with Lap and/or FTY using the LDH release assay in (A) BxPC-3, (B) KP-4, (C) PANC-1 and (D) MIA PaCa-2 cells. Data were analyzed using one-way ANOVA followed by Tukey's post hoc test. Data are shown as the mean \pm standard deviation, $\mathrm{n}=6{ }^{*} \mathrm{P}<0.05$ and ${ }^{* *} \mathrm{P}<0.01$ vs. FTY $0 \mu \mathrm{M} / \mathrm{L} a p 0 \mu \mathrm{M} .{ }^{*} \mathrm{P}<0.05$ and ${ }^{\# \#} \mathrm{P}<0.01$ vs. DMSO. (E-J) Cell death was assessed $24 \mathrm{~h}$ following treatment with Lap and/or FTY by Annexin V-FITC and PI staining. Representative flow cytometry plots of (E) BxPC-3, (G) KP-4 and (I) PANC-1 cells are presented. The cell population of (F) BxPC-3, (H) KP-4 and (J) PANC-1 cells are presented as the mean \pm standard deviation, $\mathrm{n}=3$. Data were analyzed using one-way ANOVA followed by Tukey's post hoc test. ${ }^{* * *} \mathrm{P}<0.01$ vs. FTY $0 \mu \mathrm{M} / \mathrm{Lap} 0 \mu \mathrm{M}$. ${ }^{\# \#} \mathrm{P}<0.01 \mathrm{vs}$. Lap $0 \mu \mathrm{M}$. (K-M) Cell morphology was assessed $24 \mathrm{~h}$ after combination treatment with lapatinib and FTY720 using May-Grünwald-Giemsa staining in (K) BxPC-3, (L) KP-4 and (M) PANC-1 cells. Arrows, arrowheads and asterisks indicate chromatin condensation, vacuole formation and plasma membrane disruption, respectively. Scale bar, $50 \mu \mathrm{m}$. LDH, lactate dehydrogenase; Lap, lapatinib; FTY, FTY720; AnxV, Annexin V; PI, propidium iodide; DMSO, dimethyl sulfoxide.

$5 \mu \mathrm{M}$ FTY720 was combined with $10 \mu \mathrm{M}$ lapatinib to prevent PDAC cells from detaching from the glass bottom.

Combination treatment with lapatinib and FTY720 induces death in PDAC cells. Next, it was investigated whether combination treatment with lapatinib and FTY720 induced death in PDAC cells, along with the growth inhibitory effect. As shown in Fig. 2A-D, combination treatment with lapatinib and FTY720 promoted LDH release, an indicator of cell death (41), in PDAC cells. Furthermore, combination treatment with lapatinib and FTY720 increased the Annexin V and/or PI-positive population in PDAC cells, another indicator of cell 

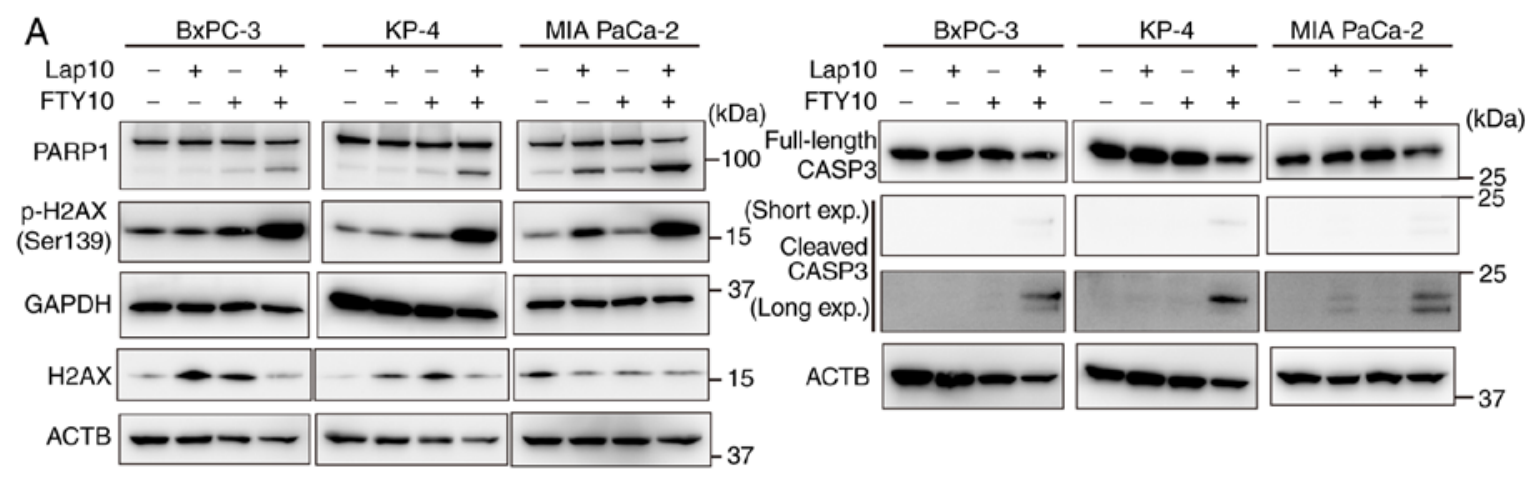

B
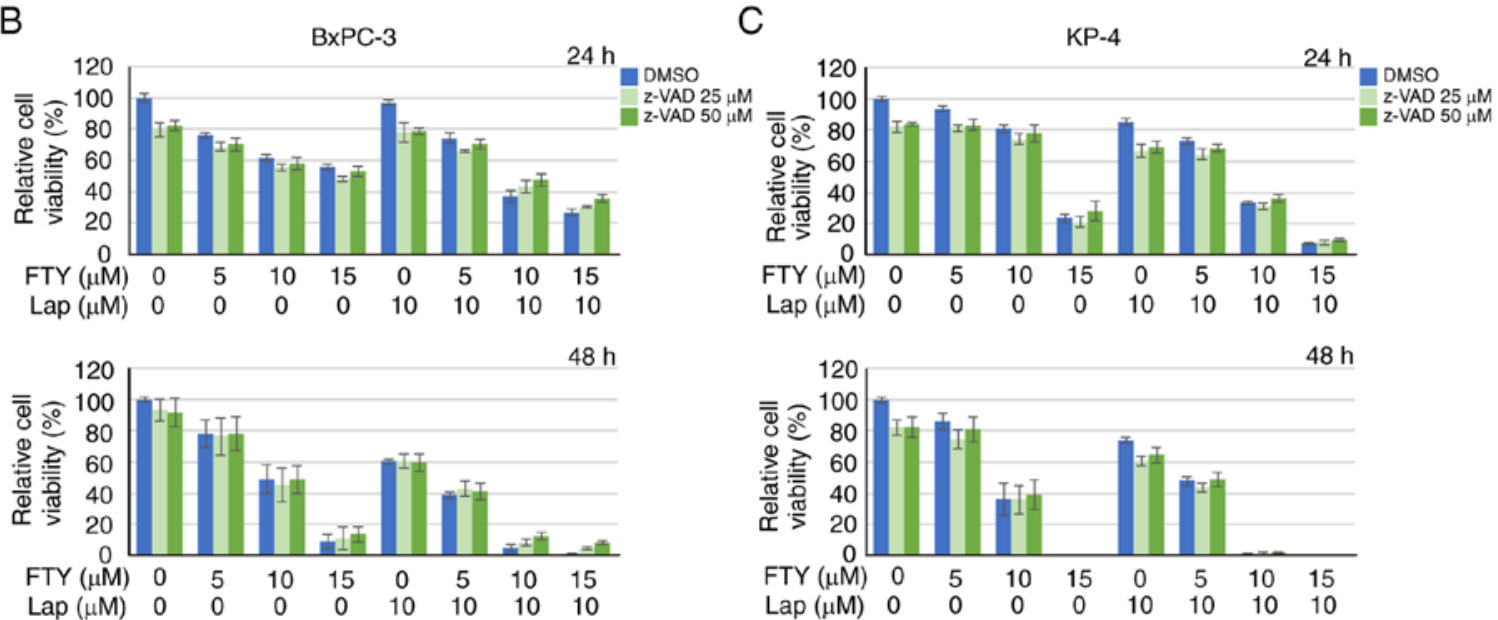

D

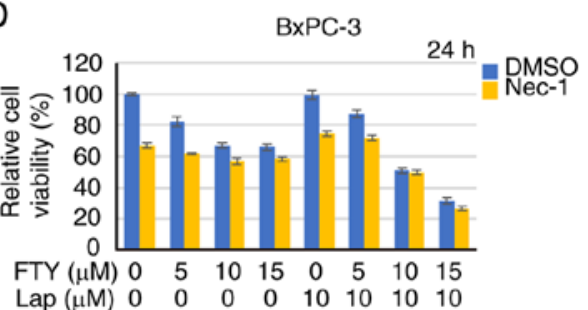

$\mathrm{E}$
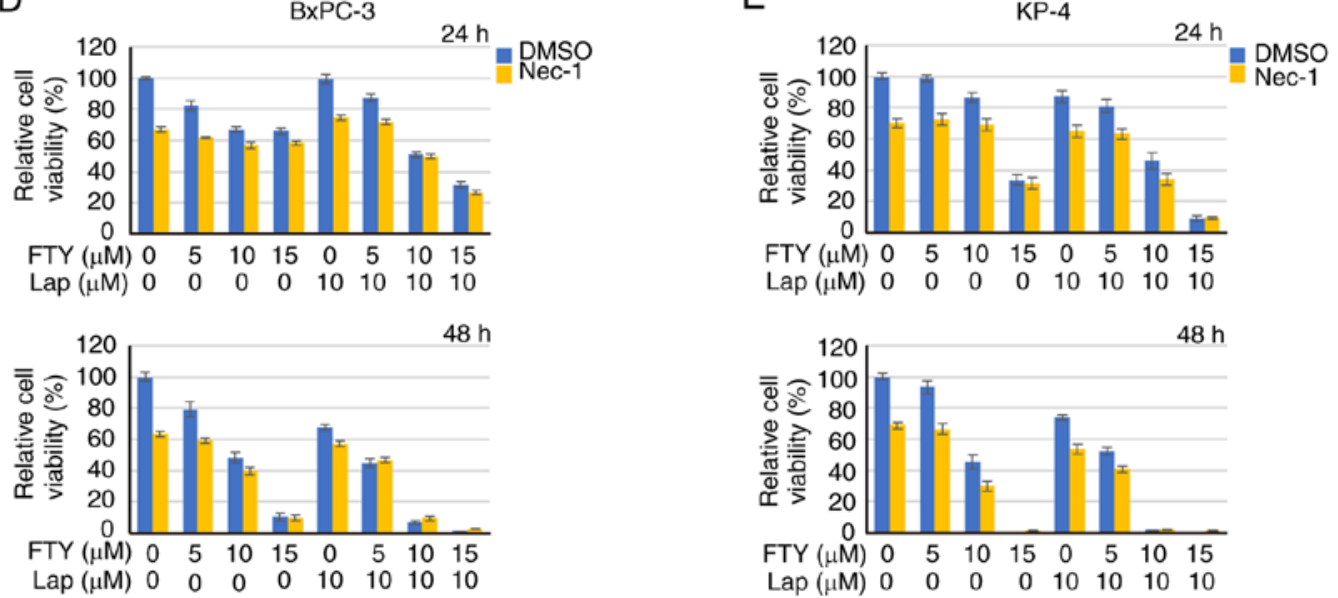

Figure 3. Non-canonical death in pancreatic ductal adenocarcinoma cells. (A) Immunoblot analysis of cleaved CASP3, PARP1 and p-H2AX expression $24 \mathrm{~h}$ after treatment with Lap $(10 \mu \mathrm{M})$ and/or FTY $(10 \mu \mathrm{M})$ in BxPC-3, KP-4 and MIA PaCa-2 cells. ACTB and GAPDH were used as loading controls. (B and C) Cell viability was assessed 24 and $48 \mathrm{~h}$ following treatment with Lap and/or FTY in the presence ( 25 or $50 \mu \mathrm{M})$ or absence of $\mathrm{z}-\mathrm{VAD}$ in (B) BxPC-3 and (C) KP-4 cells. Data were analyzed using one-way ANOVA followed by Tukey's post hoc test. Data are presented as the mean \pm standard deviation, $\mathrm{n}=6$. (D and E) Cell viability was assessed 24 and $48 \mathrm{~h}$ after treatment with Lap and/or FTY in the presence (25 $\mu \mathrm{M})$ or absence of Nec-1 in (D) BxPC-3 and (E) KP-4 cells. Data were analyzed using one-way ANOVA followed by Tukey's post hoc test. Data are presented as the mean \pm standard deviation, $\mathrm{n}=6$. CASP3, caspase-3; PARP1, poly [ADP-ribose] polymerase 1; p-, phosphorylated; H2AX, histone H2A.X; Lap, lapatinib; FTY, FTY720; z-VAD, z-VAD-FMK; Nec-1, necrostatin-1; DMSO, dimethyl sulfoxide

death (42) (Fig. 2E-J). In addition, May-Grünwald-Giemsa staining exhibited various forms of cell death, including chromatin condensation, vacuole formation and plasma membrane disruption (Fig. 2K-M).

Combination treatment with lapatinib and FTY720 induces non-canonical death in PDAC cells. Next, this study investigated the types of cell death induced by combination treatment with lapatinib and FTY720. It was observed that combination treatment with lapatinib and FTY720 markedly increased proteolytic cleavage of PARP1, a signature for apoptosis (43), and elevated levels of p-H2AX, a DNA damage marker $(44,45)$; however, lapatinib or FTY720 alone barely induced these markers (Fig. 3A). Combination treatment with lapatinib and FTY720 also induced DNA fragmentation (Fig. S5). However, cleaved CASP3, the active enzyme form responsible for PARP1 cleavage (46), was barely detected following combination treatment with lapatinib and FTY720 (Fig. 3A). Additionally, 
cell viability was slightly, but not significantly improved after combination treatment with lapatinib and FTY720 in the presence of z-VAD-FMK, a pan-caspase inhibitor, which clearly improved cell viability after treatment with staurosporine (Figs. 3B and C and S6A and B). Therefore, these findings indicated that combination treatment with lapatinib and FTY720 induced caspase-dependent apoptosis in some populations of PDAC cells, although the effect was not substantial. Furthermore, necrostatin-1, which inhibits RIPK1, a central regulator of necroptosis (47), did not improve cell viability after combination treatment with lapatinib and FTY720, although necrostatin-1 significantly improved cell viability after gefitinib treatment under starvation conditions that induce necroptosis. (Figs. 3D and E and S6C and D). Additionally, $\mathrm{N}$-acetyl-L-cysteine, known to inhibit reactive oxygen species (ROS)-induced cell death by acting as a ROS scavenger (48), improved the viability of KP-4 cells, but not BxPC-3 cells. (Fig. S7A and B). Furthermore, E64d and pepstatin A, which inhibit autophagic cell death as lysosomal protease inhibitors (49), did not improve cell viability (Fig. S7C and D). In addition, autophagic flux, which was induced by HBSS and suppressed by bafilomycin $A_{1}$, was suppressed by lapatinib and FTY720 in the PDAC cell line PANC-1, as previously reported in the NSCLC cell line A549 (18) (Fig. S7E). Collectively, combination treatment with lapatinib and FTY720 elicited non-canonical death in PDAC cells, which was not apoptotic, necroptotic or autophagic cell death and was ROS-mediated depending on the cell line.

Combination treatment with lapatinib and FTY720 impairs lysosomal function in PDAC cells. We have previously reported that FTY720 notably reduces LysoTracker staining in NSCLC cells, indicating that FTY720 inhibits the acidification of lysosome-related organelles (18). Accordingly, the present study assessed the effects of lapatinib and FTY720 on lysosomes in PDAC cells. Enlargement of LAMP2-positive vesicles, including lysosomes and endosomes, was observed in BxPC-3 and KP-4 cells (Fig. 4A-D). In addition, lapatinib and FTY720 reduced LysoTracker staining of BxPC-3 and KP-4 cells (Fig. 4E and F); combination treatment with these two drugs enhanced this effect, which was exhibited only $1 \mathrm{~h}$ after drug treatment (Figs. 4E and F and S8A and B). In addition, combination drug treatment increased the colocalization of LGALS3 and LAMP2, an indicator of enhanced lysosomal membrane permeability (50) (Figs. 5A and B and S9A and B), and suppressed the expression and maturation of the lysosomal enzyme cathepsin B (Fig. 5C). Moreover, increased LMP can disturb intracellular $\mathrm{Ca}^{2+}$ homeostasis (51). $1 \mathrm{~h}$ after combination treatment with lapatinib and FTY720, increased intracellular $\mathrm{Ca}^{2+}$ concentration was observed in BxPC-3 and KP-4 cells (Fig. 5D and E). These findings suggested that combination treatment with lapatinib and FTY720 induced LMP, which decreased lysosomal function and increased the intracellular $\mathrm{Ca}^{2+}$ concentration.

Combination treatment with lapatinib and FTY720 induces mitochondrial depolarization and ER stress in PDAC cells. Intracellular $\mathrm{Ca}^{2+}$ is exchanged among organelles, including lysosomes, mitochondria and the ER (52). Therefore, LMP and subsequent disturbance of intracellular $\mathrm{Ca}^{2+}$ homeostasis following combination treatment with lapatinib and FTY720 could indirectly impact additional organelles, including mitochondria and the ER. Considering mitochondria, immunofluorescence staining of COX IV, a mitochondrial inner membrane protein, was reduced and fragmented after combination treatment with lapatinib and FTY720 (Fig. 6A and B). In addition, to examine mitochondrial membrane potential, JC-1 dye was used, which displays fluorescence changes from green to red (magenta) depending on the mitochondrial membrane potential and reduced $\mathrm{red} / \mathrm{green}$ fluorescence intensity in depolarized mitochondria. Combination treatment resulted in mitochondrial depolarization, a hallmark of damaged mitochondria $(53,54)$, in a time-dependent manner (Fig. 6C and D).

Meanwhile, $10 \mathrm{~h}$ after combination treatment with lapatinib and FTY720, this study detected marked accumulation of CALR, a $\mathrm{Ca}^{2+}$-binding chaperone protein in the ER, suggesting the induction of ER stress (Fig. 7A and B). In addition, combination treatment altered the fluorescence staining of TGOLN2, a marker protein for the trans-Golgi network $(55,56)$, which plays an important role in vesicular trafficking from the ER to other organelles (57). Furthermore, combination treatment reduced the fluorescence kurtosis of TGOLN2, indicating the disruption of the cisternal structure of the trans-Golgi network (Fig. S10A and B). Furthermore, expression of DDIT3, an ER stress-associated gene, was upregulated in response to individual treatment with lapatinib or FTY720 and was significantly enhanced following combination treatment with lapatinib and FTY720 (Fig. 7C). Additionally, real-time ER stress monitoring analysis, based on the splicing of XBP1 mRNA and detection of the fluorescence intensity of expressed XBP1-Venus, revealed that combination treatment with lapatinib and FTY720 increased ER stress loading after $6 \mathrm{~h}$ of treatment (Fig. 7D). Collectively, these findings indicated that combination treatment with lapatinib and FTY720 induced mitochondrial damage and ER stress in PDAC cells exhibiting LMP induction.

Combination treatment with lysosome-targeted drugs elicits pronounced cytotoxic effects in PDAC cells. These data indicated that combination treatment with lapatinib and FTY720 effectively induced death in PDAC cells. To further clarify the efficacy of the lysosome-targeted drug combination, abemaciclib, an FDA-approved anticancer drug that inhibits CDK4/6, and lapatinib, instead of FTY720, were co-administered. We have previously reported that abemaciclib causes lysosomal swelling, induces LMP and increases intracellular $\mathrm{Ca}^{2+}$ in A549 cells and MCF-7 human breast cancer cells (58). Abemaciclib inhibits CDK4/6 activity and cell proliferation at sub-micromolar concentrations, inducing lysosomal dysfunction and cell death at micromolar concentrations (58). In the present study, it was observed that the growth inhibitory effect of lapatinib on PDAC cells was significantly enhanced following coadministration with abemaciclib (Fig. 8A-D), as well as after combined treatment with FTY720 (Fig. 1). Likewise, the growth inhibitory effect of lapatinib on PDAC cells was significantly enhanced after coadministration with the FDA-approved drug HCQ, which is known to induce the potent basification of lysosomes $(59,60)$ (Fig. 8E and F). In addition, coadministration of abemaciclib and FTY720 or abemaciclib and HCQ enhanced the growth inhibitory effect on PDAC cells (Fig. S11A-D). Coadministration of lapatinib and abemaciclib or lapatinib and HCQ also induced 
A

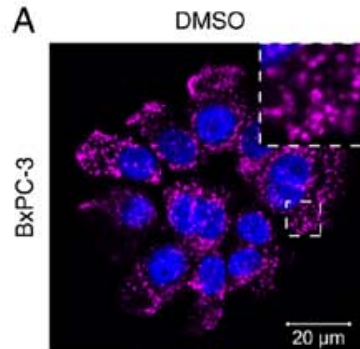

LAMP2/DAPI

C

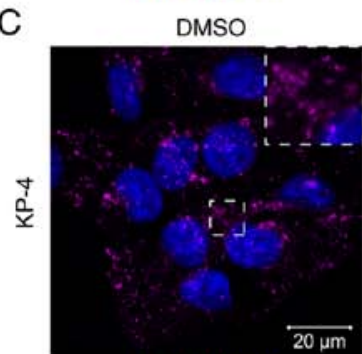

E
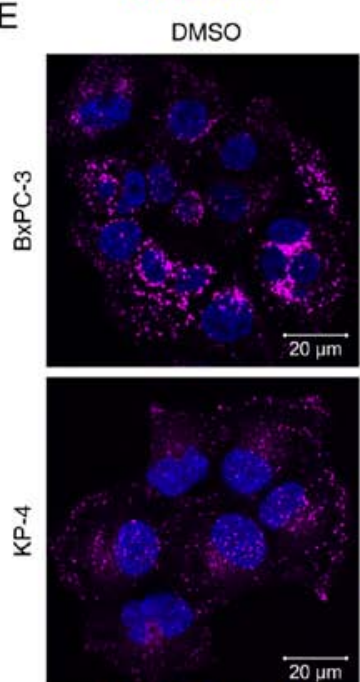

LysoTracker/Hoechst
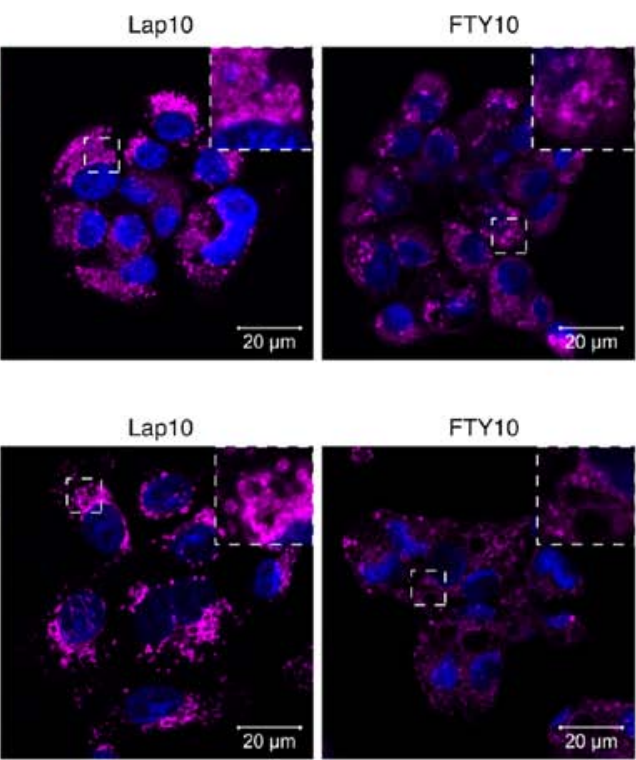

Lap10
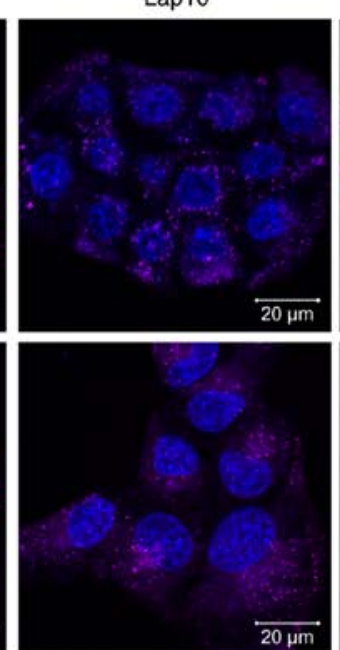

$\overline{20 \mu \mathrm{m}}$

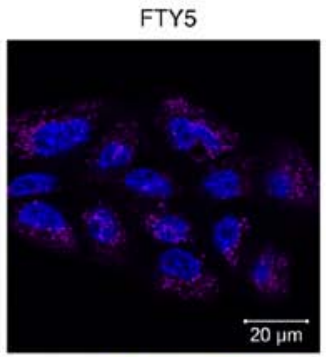

B

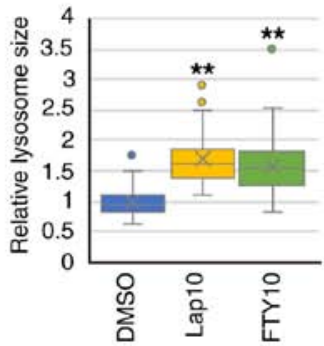

D

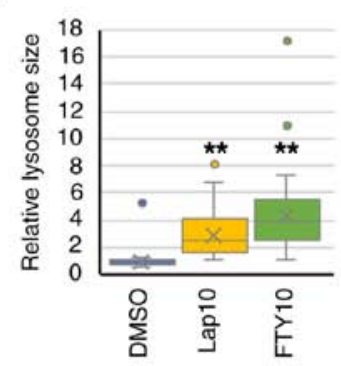

Lap10/FTY5

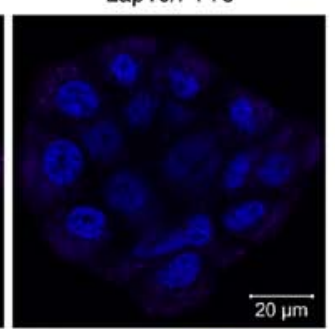

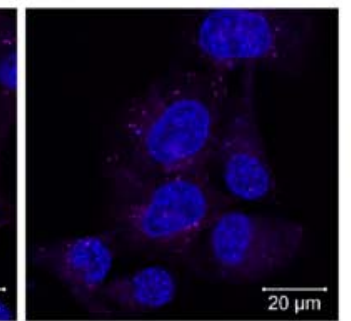
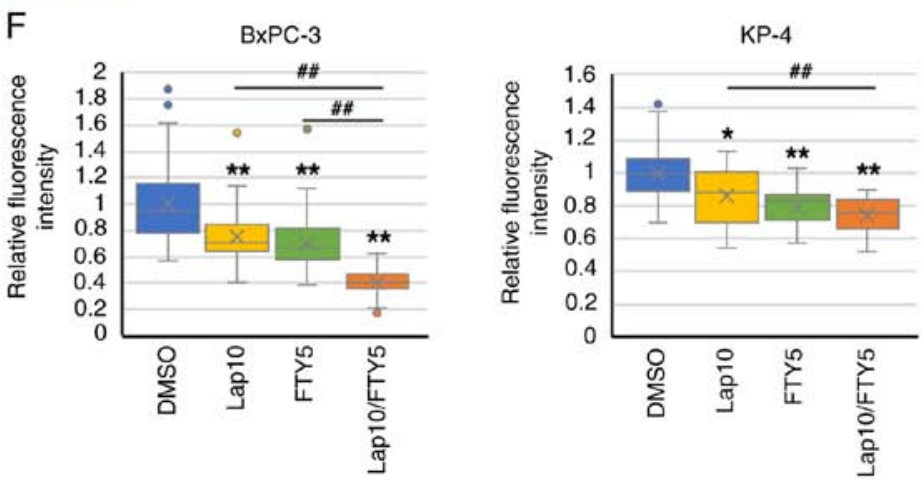

Figure 4. Impact of Lap and FTY treatment on lysosomal morphology and functions. (A) Immunofluorescence analysis of LAMP2 (magenta) $10 \mathrm{~h}$ after treatment with Lap (10 $\mu \mathrm{M})$ or FTY (10 $\mu \mathrm{M})$ in BxPC-3 cells. Dashed boxed regions are shown at high magnification in the inset. Scale bar, $20 \mu \mathrm{m}$. (B) Relative lysosomal sizes in each condition of BxPC-3 cells from (A) are shown. Data were analyzed using Kruskal-Wallis with Dunn's post hoc test. The box extends from the lower to upper quartiles. The middle line represents the median value. $\mathrm{X}$ indicates the mean value. The whiskers represent the minimum to maximum values, except for outliers, which are indicated by dots. $\mathrm{n}=50$. "* $\mathrm{P}<0.01 \mathrm{vs.}$. DMSO. (C) Immunofluorescence analysis of LAMP2 (magenta) $10 \mathrm{~h}$ after treatment with Lap $(10 \mu \mathrm{M})$ or FTY $(10 \mu \mathrm{M})$ in KP-4 cells. Dashed boxed regions are shown at high magnification in the inset. Scale bar, $20 \mu \mathrm{m}$. (D) Relative lysosomal sizes in each condition of KP-4 cells from (C) are presented. Data were analyzed using Kruskal-Wallis with Dunn's post hoc test. The box extends from the lower to upper quartiles. The middle line represents the median value. $X$ indicates the mean value. The whiskers represent the minimum to maximum values, except for outliers, which are indicated by dots. $\mathrm{n}=50 .{ }^{* *} \mathrm{P}<0.01$ vs. DMSO. (E) LysoTracker staining (magenta) $1 \mathrm{~h}$ after treatment with Lap $(10 \mu \mathrm{M})$ and/or FTY $(5 \mu \mathrm{M})$ in BxPC-3 and KP-4 cells. Scale bar, $20 \mu \mathrm{m}$. (F) Relative mean fluorescence intensities of LysoTracker in each condition of BxPC-3 and KP-4 cells from (E) are shown. Data were analyzed using Kruskal-Wallis with Dunn's post hoc test. The box extends from the lower to upper quartiles. The middle line represents the median value. $X$ indicates the mean value. The whiskers represent the minimum to maximum values, except for outliers, which are indicated by dots. BxPC-3, n=36; KP-4, $\mathrm{n}=23$. ${ }^{*} \mathrm{P}<0.05$ and ${ }^{* *} \mathrm{P}<0.01$ vs. DMSO. ${ }^{\# /} \mathrm{P}<0.01$ vs. Lap10/FTY5. LAMP, lysosome-associated membrane protein; Lap, lapatinib; FTY, FTY720; DMSO, dimethyl sulfoxide. 
A

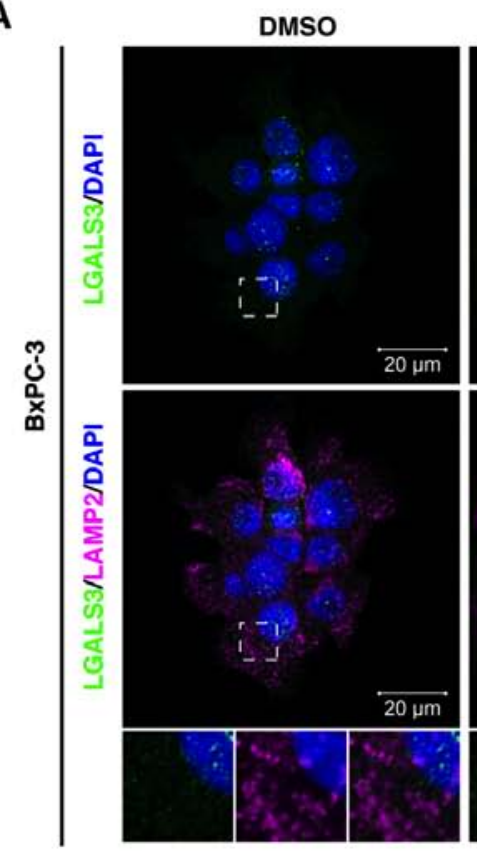

B

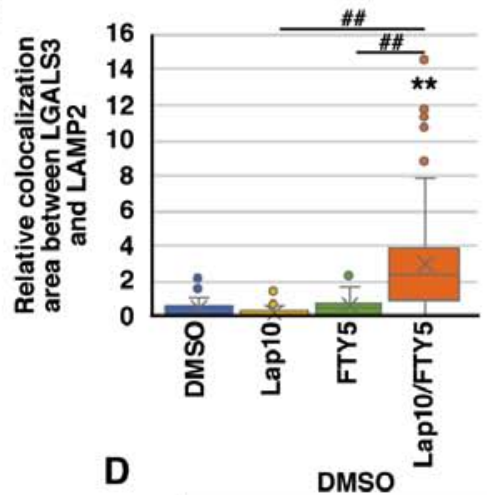

D
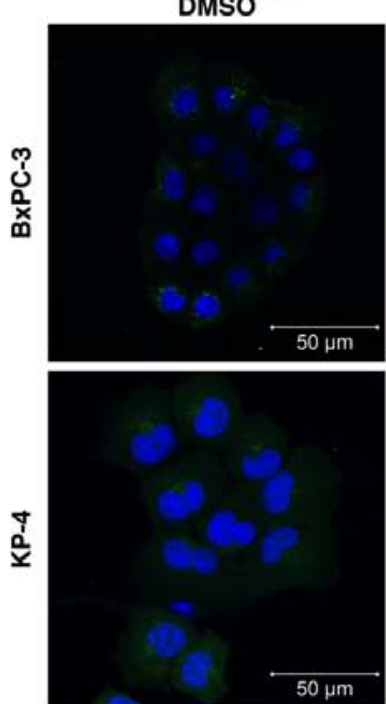

Fluo-8-AM/Hoechst
Lap10
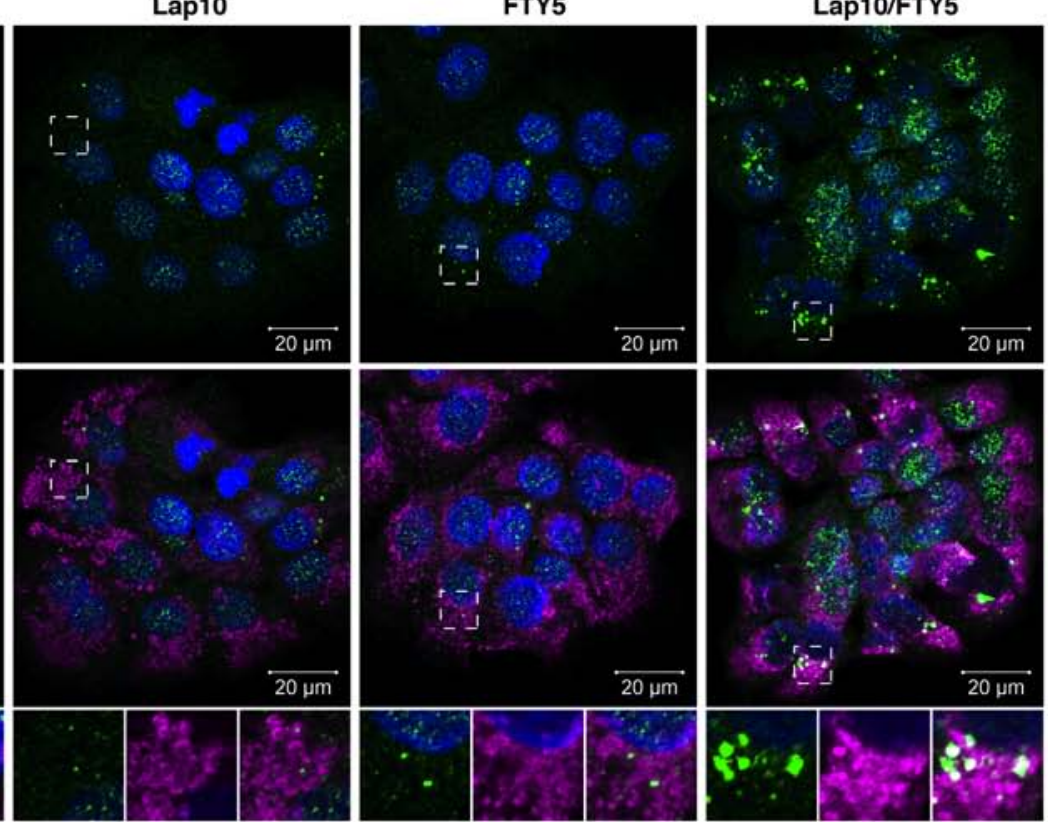

C
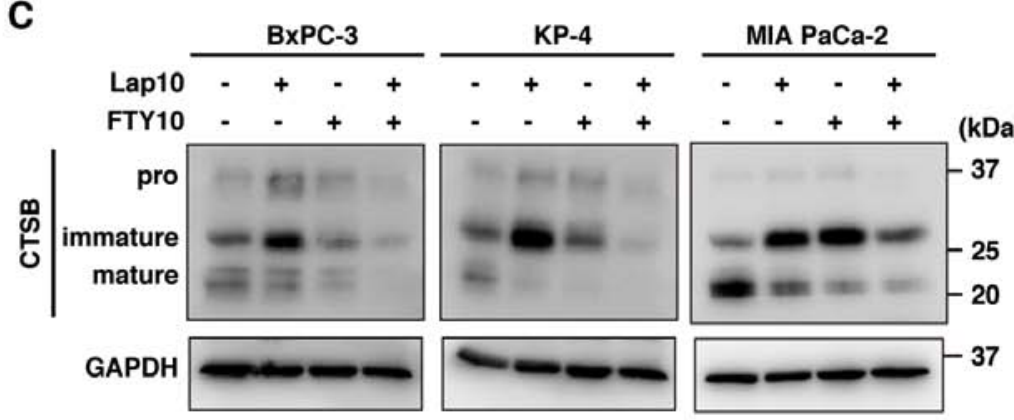

E
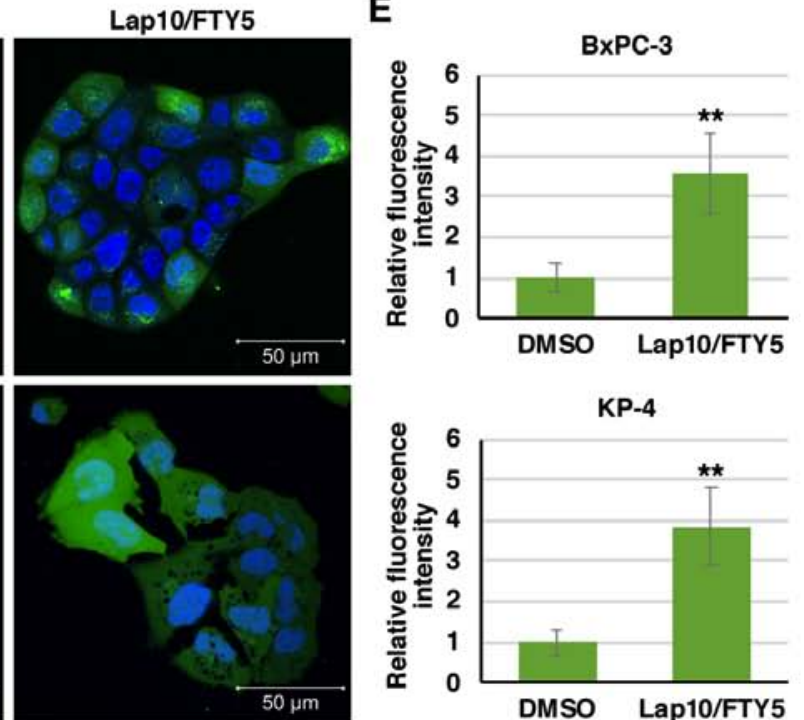

Figure 5. Combination treatment with Lap and FTY induces lysosomal membrane permeabilization. (A) Immunofluorescence analysis of LAMP2 (magenta) and LGALS3 (green) $10 \mathrm{~h}$ after treatment with Lap $(10 \mu \mathrm{M})$ and/or FTY $(5 \mu \mathrm{M})$ in BxPC-3 cells. The dashed boxed regions are shown at high magnification at the bottom. Scale bar, $20 \mu \mathrm{m}$. (B) Colocalization of fluorescence between LGALS3 and LAMP2 in BxPC-3 cells from (A) was analyzed using ImageJ. Data were analyzed using Kruskal-Wallis with Dunn's post hoc test. The box extends from the lower to upper quartiles. The middle line represents the median value. $\mathrm{X}$ indicates the mean value. The whiskers represent the minimum to maximum values, except for outliers, which are indicated by dots. $\mathrm{n}=26 .{ }^{* *} \mathrm{P}<0.01$ vs. DMSO. ${ }^{\# \#} \mathrm{P}<0.01$ vs. Lap $10 \mu \mathrm{M} / \mathrm{FTY} 5 \mu \mathrm{M}$. (C) Immunoblot analysis of CTSB expression $24 \mathrm{~h}$ after treatment with Lap (10 $\left.\mu \mathrm{M}\right)$ and/or FTY (10 $\left.\mu \mathrm{M}\right)$ in BxPC-3, KP-4 and MIA PaCa-2 cells. The membrane for CTSB was stripped and reprobed for GAPDH as the loading control. (D) Intracellular Ca ${ }^{2+}$ concentrations were assessed $1 \mathrm{~h}$ after combination treatment with Lap $(10 \mu \mathrm{M})$ and FTY $(5 \mu \mathrm{M})$ in BxPC-3 and KP-4 cells using Fluo-8-AM (green). Scale bar, $50 \mu \mathrm{m}$. (E) Relative mean fluorescence intensities of Fluo-8-AM in BxPC-3 and KP-4 cells from (D) are presented. Data were analyzed using an unpaired two-tailed Student's t-test. Data are presented as the mean \pm standard deviation, BxPC-3, n=5; KP-4, n=4. ${ }^{* *} \mathrm{P}<0.01$ vs. DMSO. LAMP, lysosome-associated membrane protein; CTSB, cathepsin B; Lap, lapatinib; FTY, FTY720; LGALS3, galectin-3; $\mathrm{Ca}^{2+}$, calcium. 
A
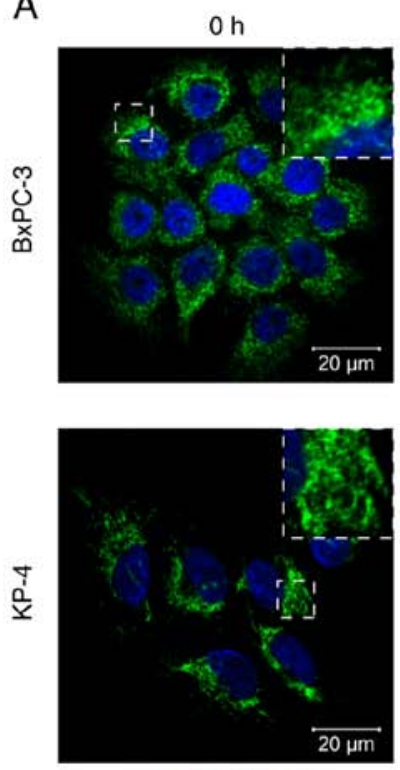

COX IV/DAPI

C
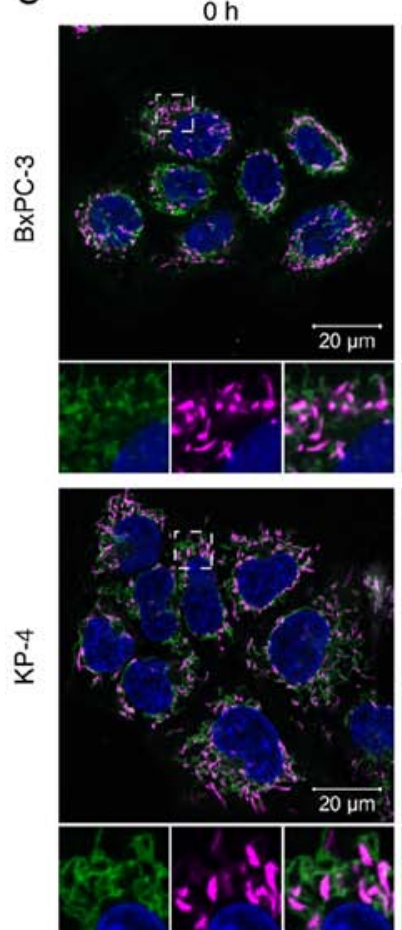

JC1poly/JC1mono/Hoechst
$4 \mathrm{~h}$
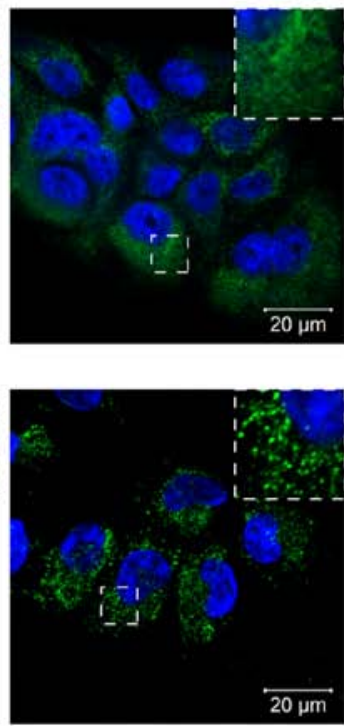

$\overline{20 \mu m}$
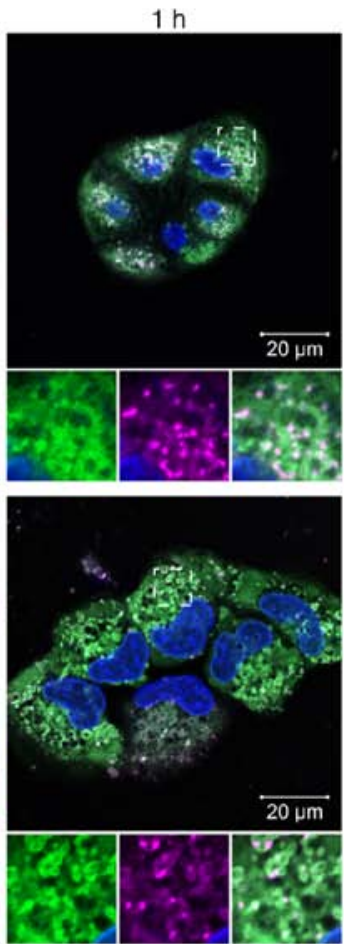

$10 \mathrm{~h}$
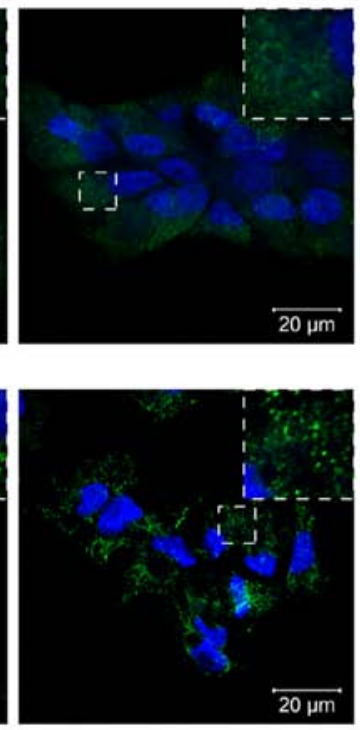

$\stackrel{20 \mu \mathrm{m}}{ }$

Leno
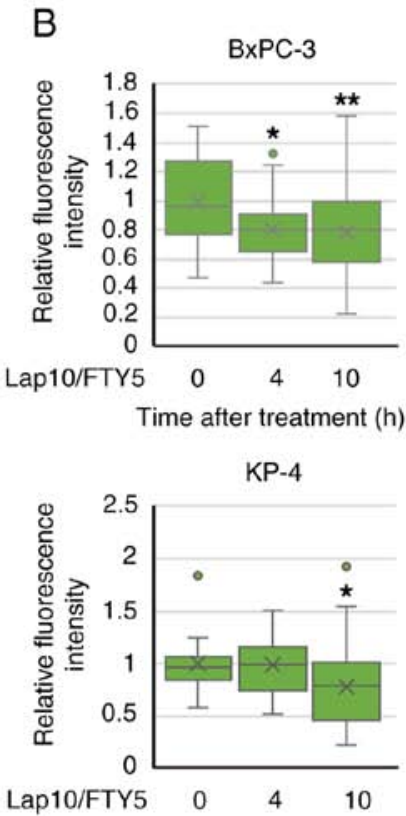

Time after treatment (h)

D
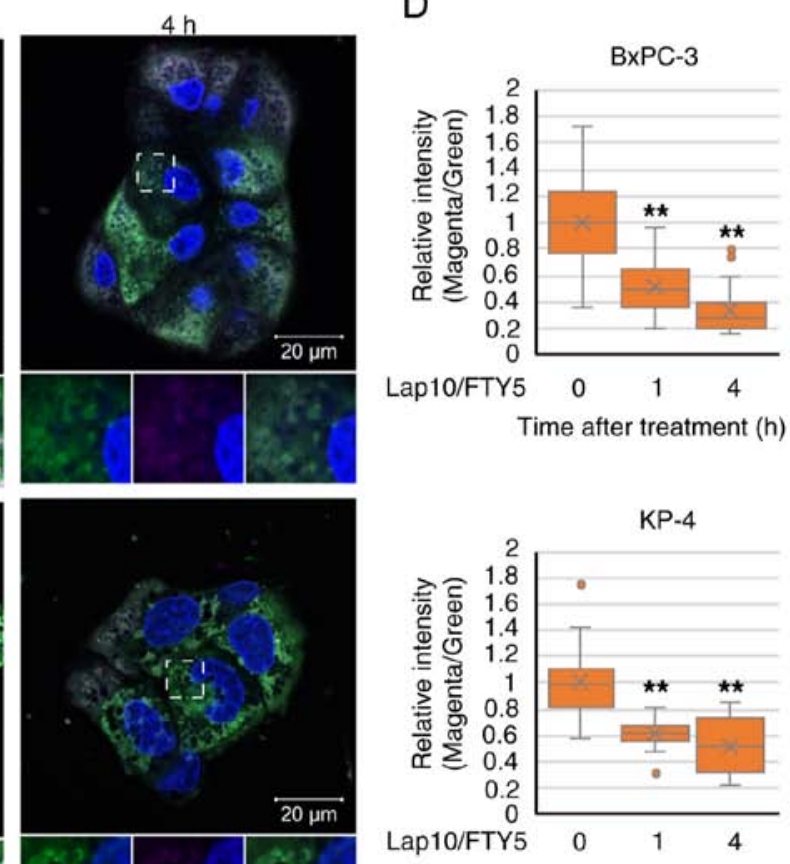

Time after treatment (h)

Figure 6. Impact of combination treatment with Lap and FTY on mitochondria. (A) Immunofluorescence analysis of COX IV (green) at indicated time points $(0,4$ and $10 \mathrm{~h})$ following combination treatment with Lap $(10 \mu \mathrm{M})$ and FTY $(5 \mu \mathrm{M})$ in BxPC-3 and KP-4 cells. Dashed boxed regions are shown at high magnification in the inset. Scale bar, $20 \mu \mathrm{m}$. (B) Relative mean fluorescence intensities of COX IV at each time point for BxPC-3 and KP-4 cells from (A) are shown. Data were analyzed using Kruskal-Wallis with Dunn's post hoc test. The box extends from the lower to upper quartiles. The middle line represents the median value. $\mathrm{X}$ indicates the mean value. The whiskers represent the minimum to maximum values, except for outliers, which are indicated by dots. BxPC-3, $\mathrm{n}=37$; KP-4, $\mathrm{n}=19$. ${ }^{*} \mathrm{P}<0.05$ and ${ }^{* *} \mathrm{P}<0.01$ vs. 0 h. (C) Mitochondrial membrane potential was assessed 1 and $4 \mathrm{~h}$ after combination treatment with Lap (10 $\left.\mu \mathrm{M}\right)$ and FTY $(5 \mu \mathrm{M})$ in BxPC-3 and KP-4 cells using JC-1 (magenta and green). Scale bar, $20 \mu \mathrm{m}$. (D) Relative mean fluorescence intensities (magenta/green) of JC-1 in BxPC-3 and KP-4 cells from (C) are presented. Data were analyzed using Kruskal-Wallis with Dunn's post hoc test. The box extends from the lower to upper quartiles. The middle line represents the median value. $\mathrm{X}$ indicates the mean value. The whiskers represent the minimum to maximum values, except for outliers, which are indicated by dots. BxPC-3, n=31; KP-4, n=26. ${ }^{* *} \mathrm{P}<0.01$ vs. 0 h. COX IV, cytochrome c oxidase subunit 4 ; Lap, lapatinib; FTY, FTY720.

cell death (Fig. 8G-J). Moreover, coadministration of lapatinib and abemaciclib or lapatinib and HCQ reduced LysoTracker staining (Fig. 9A-D), increased the colocalization of LGALS3 and LAMP2 (Fig. 9E-H) and enhanced the intracellular $\mathrm{Ca}^{2+}$ concentration in BxPC-3 cells (Fig. 9I-L), as observed following coadministration of lapatinib and FTY720. These results further suggested that the combination of lysosome-targeted drugs elicits pronounced cytotoxic effects on PDAC cells. 
A
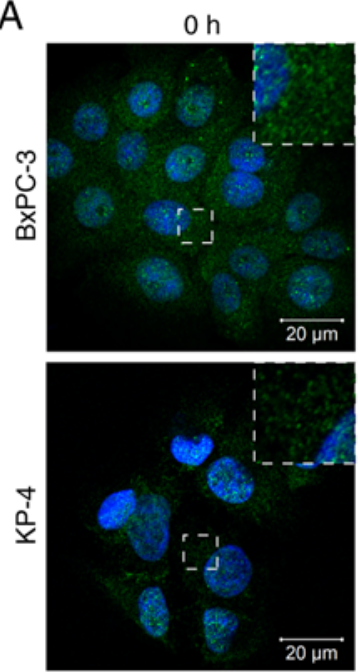

CALR/DAPI

B
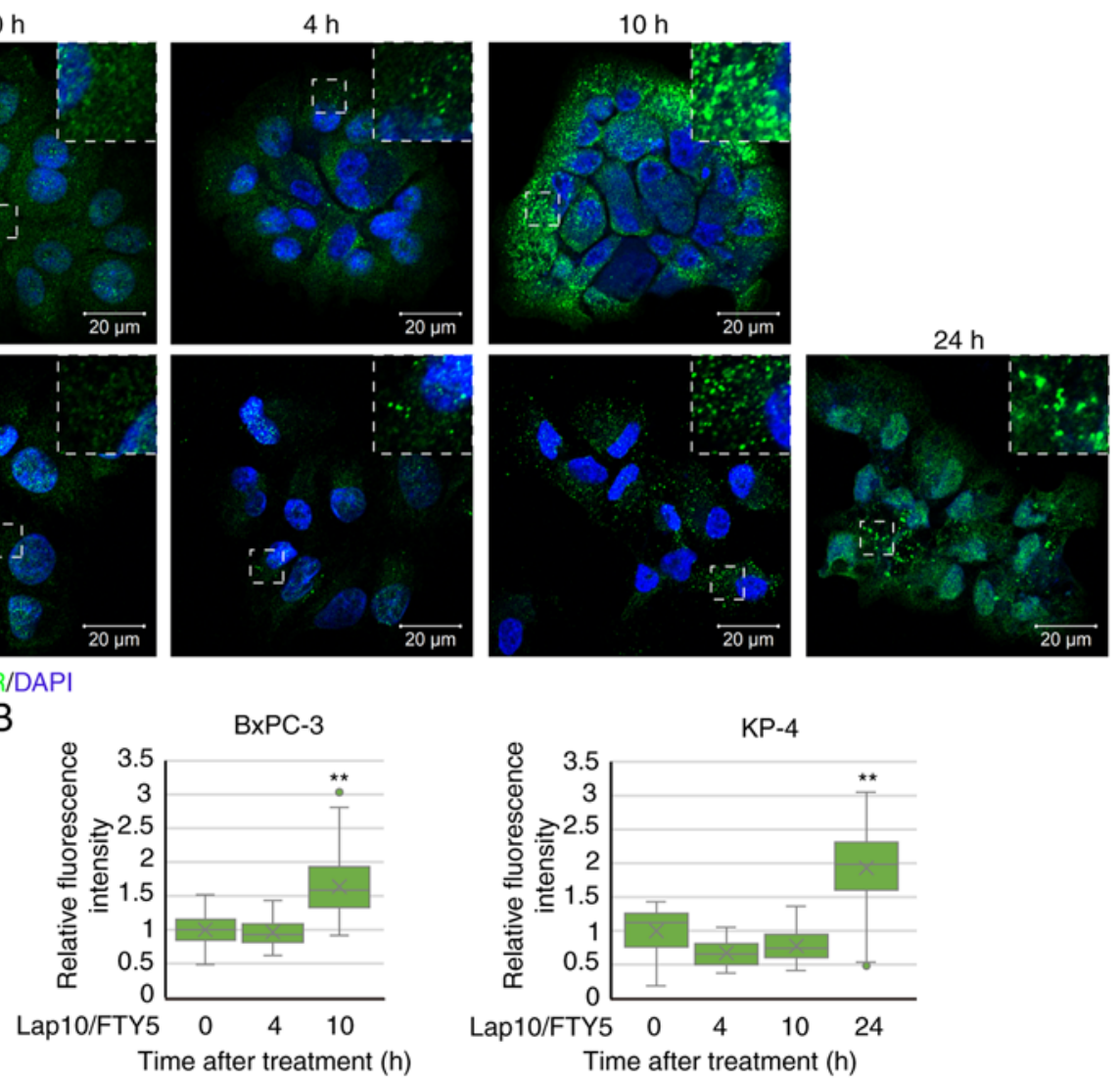

C
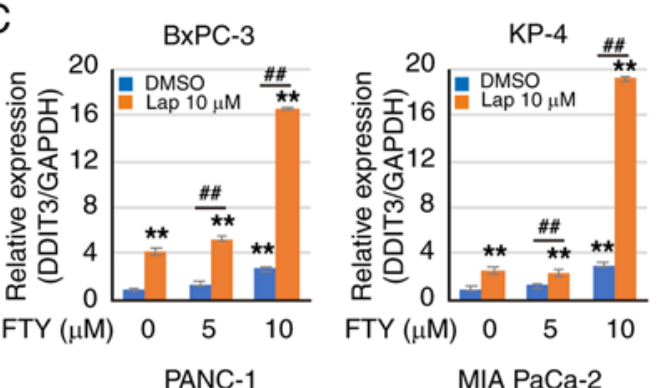

$\mathrm{D}$

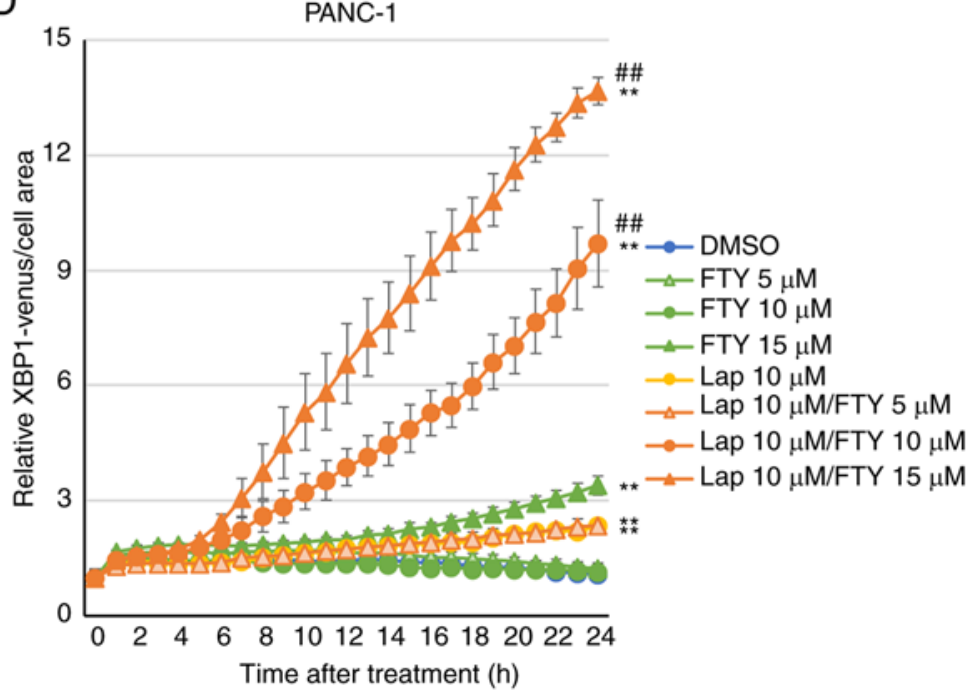

Figure 7. Impact of combination treatment with Lap and FTY on the endoplasmic reticulum. (A) Immunofluorescence analysis of CALR (green) at indicated time points $(0,4,10$ and $24 \mathrm{~h})$ after combination treatment with Lap $(10 \mu \mathrm{M})$ and FTY $(5 \mu \mathrm{M})$ in BxPC-3 and KP-4 cells. Dashed boxed regions are shown at high magnification in the inset. Scale bar, $20 \mu \mathrm{m}$. (B) Relative mean fluorescence intensities of CALR at each time point in BxPC-3 and KP-4 cells from (A) are shown. Data were analyzed using Kruskal-Wallis with Dunn's post hoc test. The box extends from the lower to upper quartiles. The middle line represents the median value. X indicates the mean value. The whiskers represent the minimum to maximum values, except for outliers, which are indicated by dots. BxPC-3, $\mathrm{n}=37$; KP-4, n=19. ${ }^{* *} \mathrm{P}<0.01$ vs. 0 h. (C) BxPC-3, KP-4, PANC-1 and MIA PaCa-2 cells were treated with Lap and/or FTY for 24 h. DDIT3 expression was determined via quantitative PCR and normalized to GAPDH. Data were analyzed using one-way ANOVA followed by Tukey's post hoc test. Data are presented as the mean \pm standard deviation, $\mathrm{n}=4$. ${ }^{* *} \mathrm{P}<0.01$ vs. FTY $0 \mu \mathrm{M} /$ Lap $0 \mu \mathrm{M}$. ${ }^{\# \#} \mathrm{P}<0.01$ vs. DMSO. (D) PANC-1/XBP1-Venus cells were treated with Lap and/or FTY. The fluorescence intensities derived from XBP1-Venus were monitored over $24 \mathrm{~h}$. Data were analyzed using two-way ANOVA followed by Bonferroni's post hoc test. Data are presented as the mean \pm standard deviation, $\mathrm{n}=4$. ${ }^{* *} \mathrm{P}<0.01$ vs. DMSO. ${ }^{\#} \mathrm{P}<0.01$ vs. Lap $10 \mu \mathrm{M}$. CALR, calreticulin; Lap, lapatinib; FTY, FTY720; DMSO, dimethyl sulfoxide; DDIT3, DNA damage inducible transcript 3.

Lysosomal cholesterol accumulation suppresses non-canonical cell death induced by combination treatment with lapatinib and FTY720 in PDAC cells. To determine whether lysosomal dysfunction can be directly attributed to non-canonical death and multiple organelle dysfunctions in PDAC cells, the effects of U18666A, which can reportedly strengthen lysosomal membrane by accumulating cholesterol in the lysosomal membrane $(61,62)$, were analyzed. U18666A-induced 

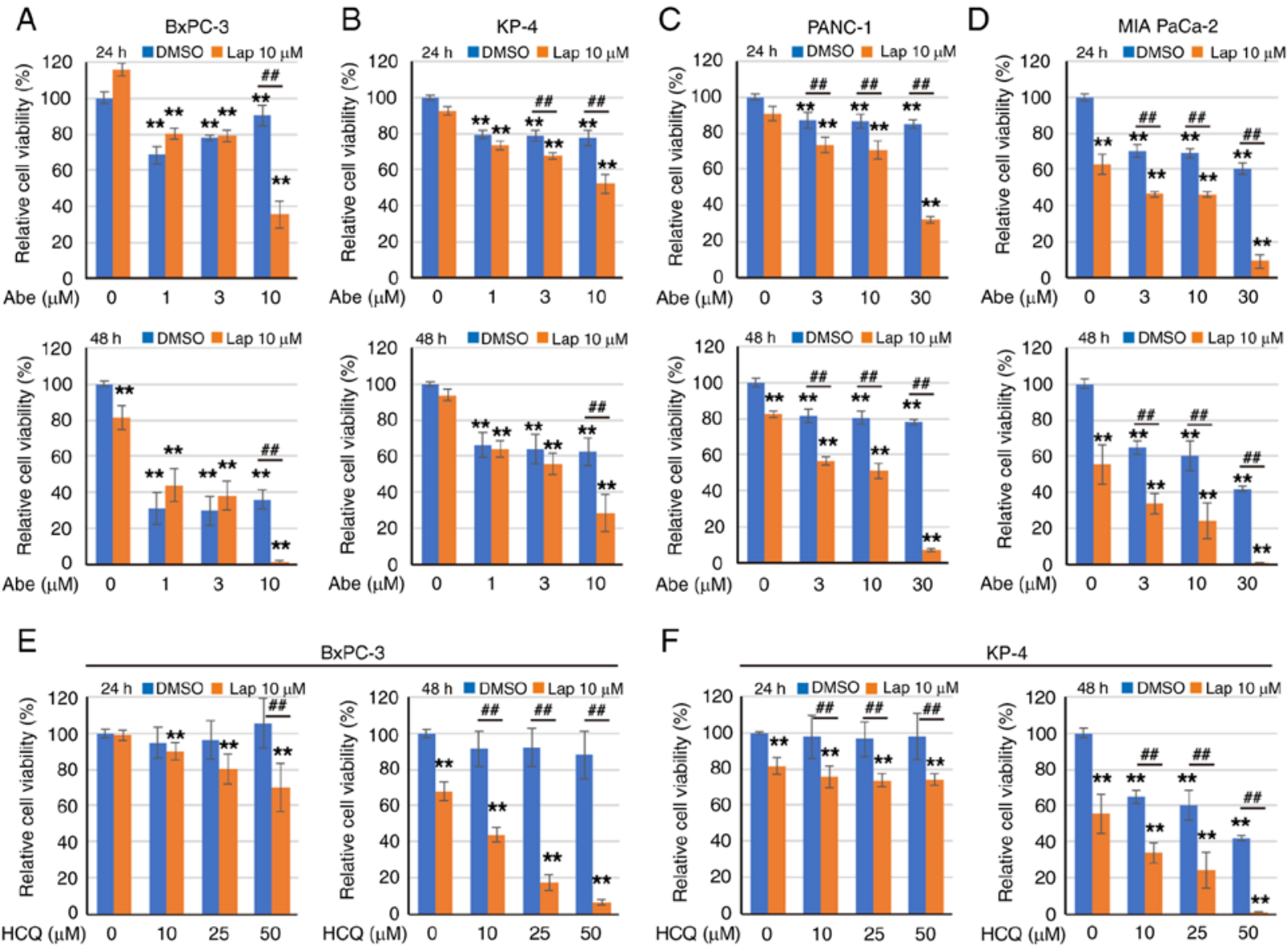

BxPC-3

$\mathrm{F}$
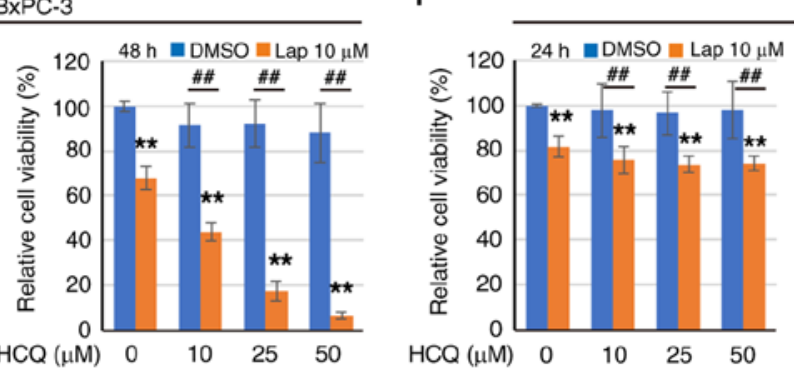

KP-4

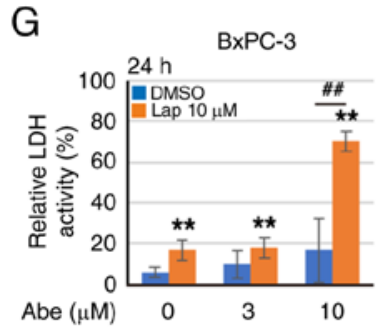

$\mathrm{H}$
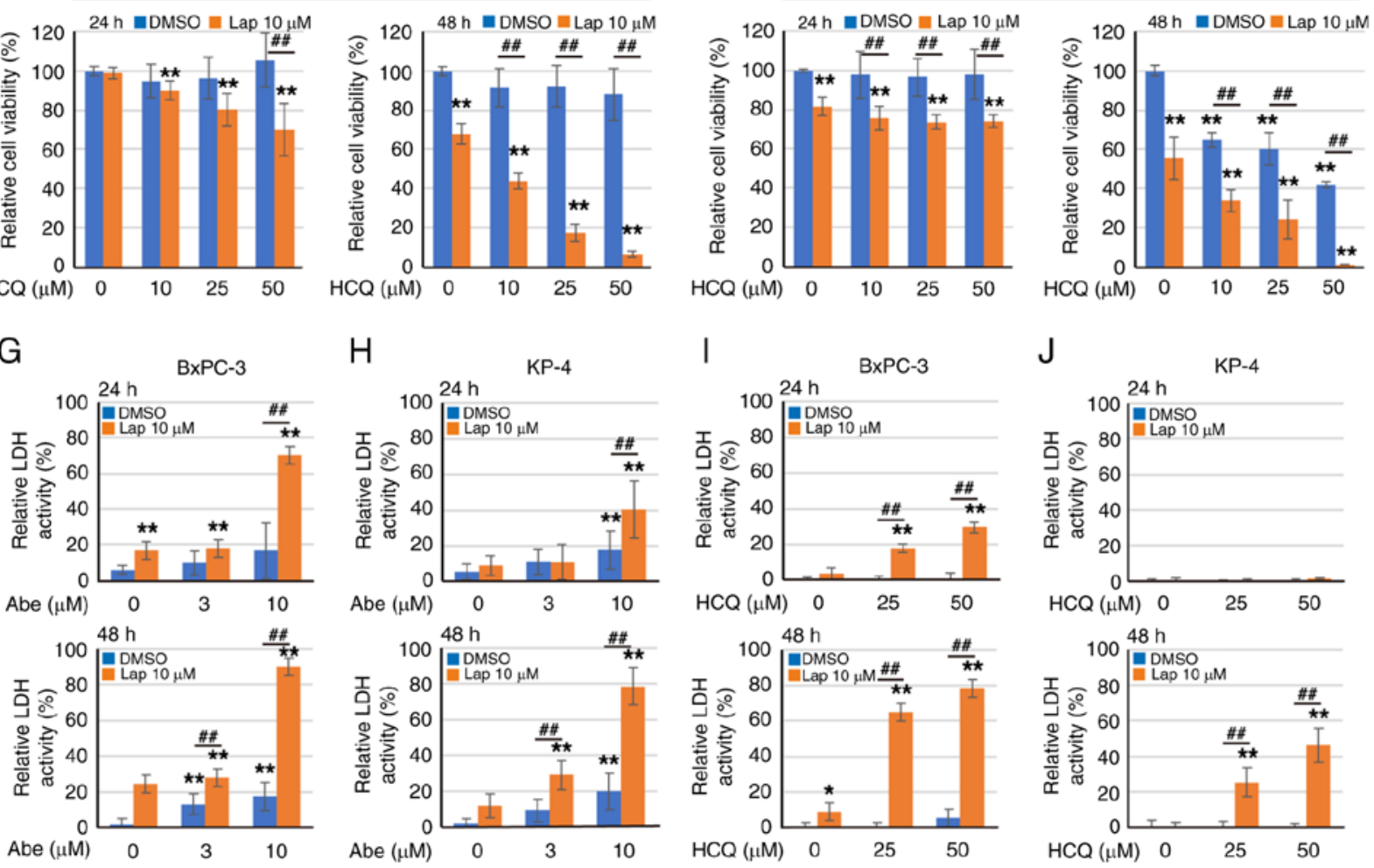

$\mathrm{J}$
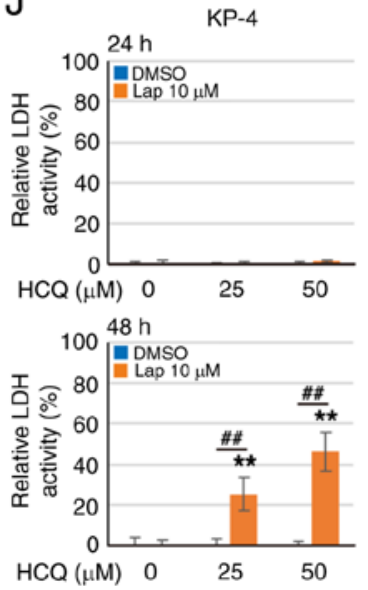

Figure 8. Cytotoxic activity of the lysosome-targeted drug combination in pancreatic ductal adenocarcinoma cells. (A-D) Cell viability was assessed $24 \mathrm{and} 48 \mathrm{~h}$ after treatment with Lap and/or Abe in (A) BxPC-3, (B) KP-4, (C) PANC-1 and (D) MIA PaCa-2 cells. Data were analyzed using one-way ANOVA followed by Tukey's post hoc test. Data are presented as the mean \pm standard deviation, $\mathrm{n}=6 .{ }^{* *} \mathrm{P}<0.01$ vs. Abe $0 \mu \mathrm{M} / \mathrm{Lap} 0 \mu \mathrm{M}$. ${ }^{\# \prime} \mathrm{P}<0.01$ vs. DMSO. (E and F) Cell viability was assessed 24 and $48 \mathrm{~h}$ after treatment with Lap and/or HCQ in (E) BxPC-3 and (F) KP-4 cells. Data were analyzed using one-way ANOVA followed by Tukey's post hoc test. Data are presented as the mean \pm standard deviation, $\mathrm{n}=6$. ${ }^{* *} \mathrm{P}<0.01 \mathrm{vs}$. $\mathrm{HCQ} 0 \mu \mathrm{M} / \mathrm{Lap} 0 \mu \mathrm{M}$. ${ }^{\# \#} \mathrm{P}<0.01$ vs. DMSO. (G and $\mathrm{H}$ ) Cytotoxicity was assessed at 24 and $48 \mathrm{~h}$ following treatment with Lap and/or Abe using the LDH release assay in (G) BxPC-3 and (H) KP-4 cells. Data were analyzed using one-way ANOVA followed by Tukey's post hoc test. Data are shown as the mean \pm standard deviation, $\mathrm{n}=6 .{ }^{* *} \mathrm{P}<0.01 \mathrm{vs}$. Abe $0 \mu \mathrm{M} / \mathrm{Lap} 0 \mu \mathrm{M}$. ${ }^{\# \prime} \mathrm{P}<0.01$ vs. DMSO. (I and J) Cytotoxicity was assessed at 24 and $48 \mathrm{~h}$ following treatment with Lap and/or HCQ using the LDH release assay in (I) BxPC-3 and (J) KP-4 cells. Data were analyzed using one-way ANOVA followed by Tukey's post hoc test. Data are shown as the mean \pm standard deviation, $\mathrm{n}=6$. ${ }^{*} \mathrm{P}<0.05$ and ${ }^{* *} \mathrm{P}<0.01$ vs. HCQ $0 \mu \mathrm{M} /$ Lap $0 \mu \mathrm{M}$. ${ }^{\# /} \mathrm{P}<0.01$ vs. DMSO. Lap, lapatinib; FTY, FTY720; DMSO, dimethyl sulfoxide; HCQ, hydroxychloroquine; Abe, abemaciclib; LDH, lactate dehydrogenase.

cholesterol accumulation was confirmed by filipin staining in KP-4 cells (Fig. S12A). In PDAC cells, the growth inhibitory effect of combination treatment with lapatinib and FTY720 was effectively suppressed by U18666A (Fig. S12B-D). In addition, U18666A restored the reduced LysoTracker staining after combination treatment with lapatinib and FTY720 in KP-4 cells (Fig. 10A and B). In BxPC-3 cells, U18666A did not restore the decreased LysoTracker staining after combination 
A

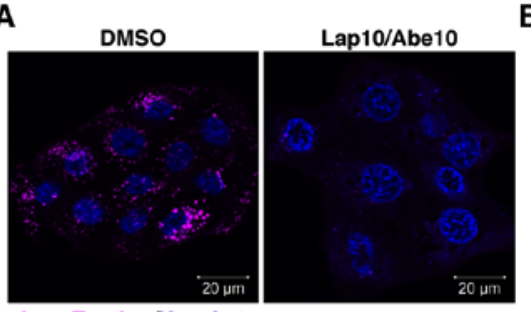

LysoTracker/Hoechst

E
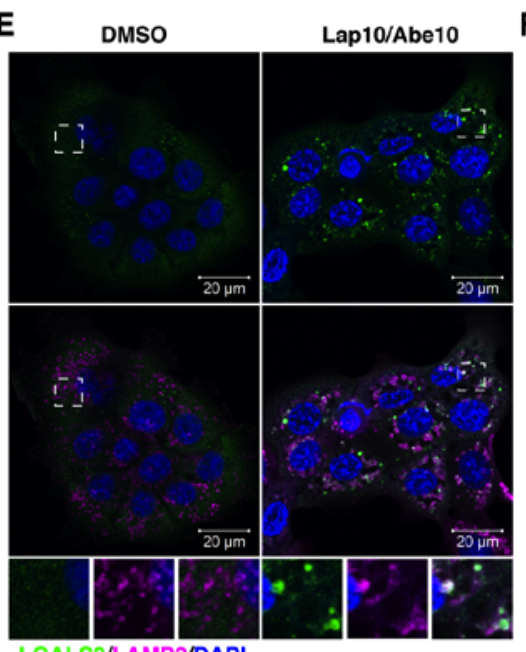

LGALS3/LAMP2/DAPI

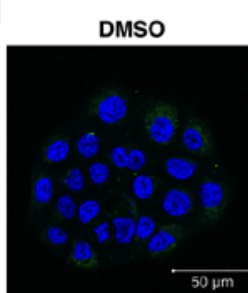

Fluo-8-AM/Hoechst

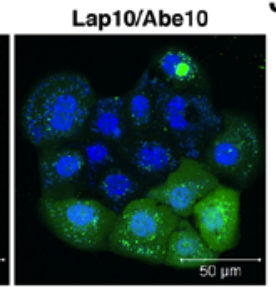

B $25 \quad C$

C

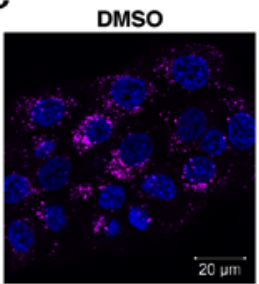

LysoTracker/Hoechst

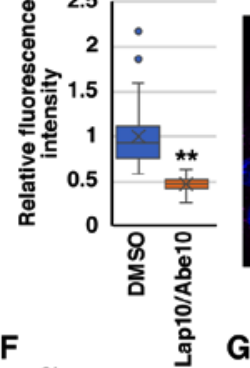

G DMso
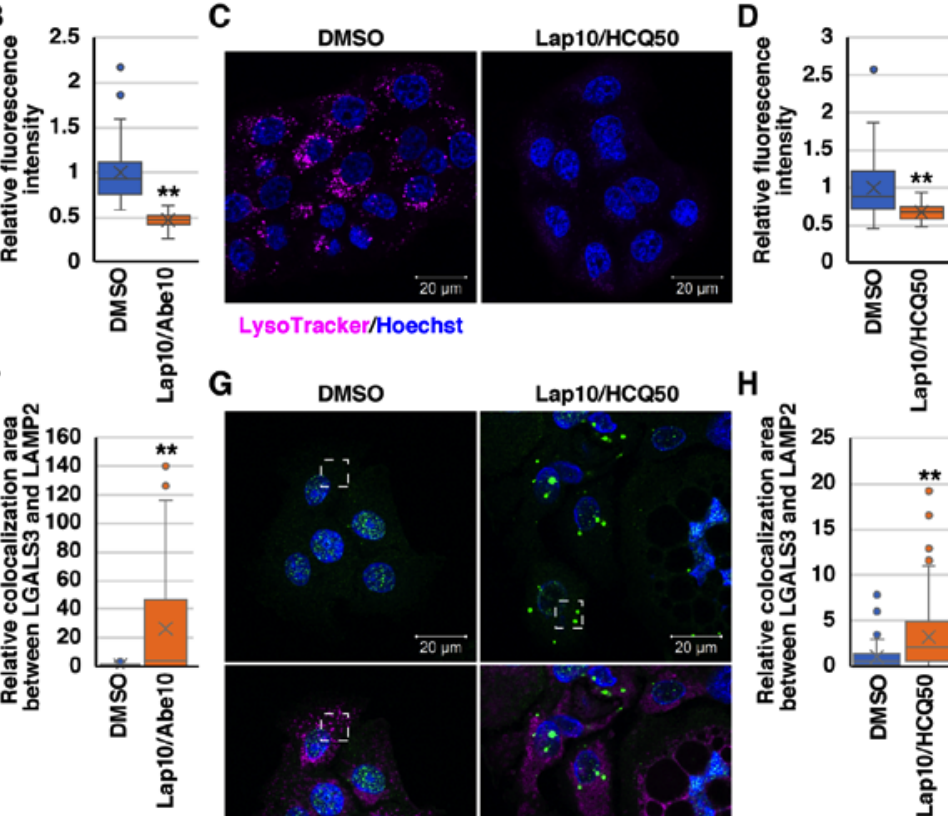

Lap10/HCQ50
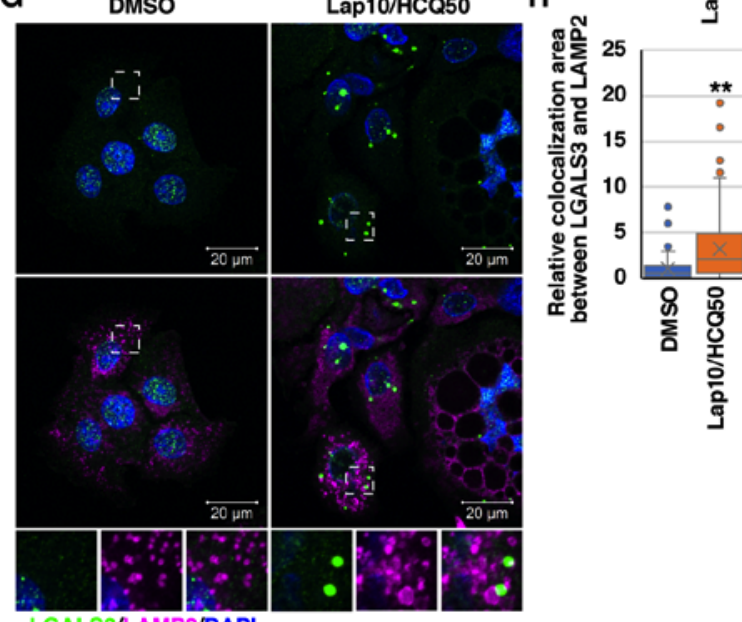

K
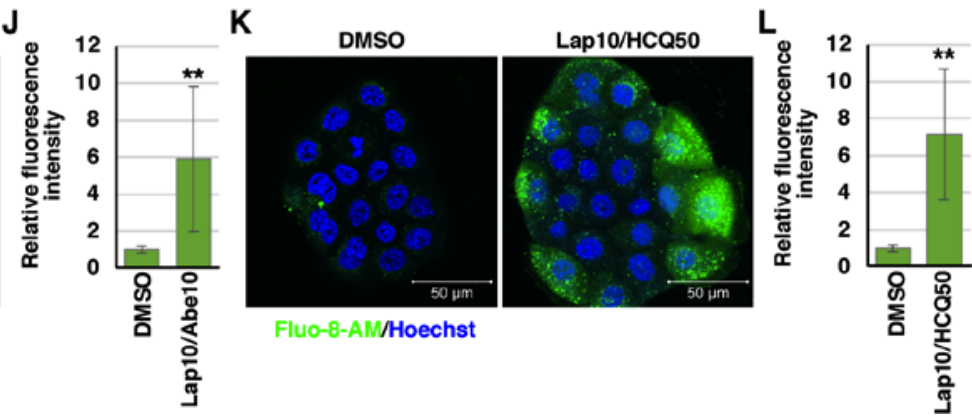

Figure 9. Impact of the lysosome-targeted drug combination on lysosomes in pancreatic ductal adenocarcinoma cells. (A) LysoTracker staining (magenta) $1 \mathrm{~h}$ after treatment with Lap $(10 \mu \mathrm{M})$ and Abe $(10 \mu \mathrm{M})$ in BxPC-3 cells. Scale bar, $20 \mu \mathrm{m}$. (B) Relative mean fluorescence intensities of LysoTracker in each condition of BxPC-3 cells from (A) are shown. Data were analyzed using Mann Whitney U test. The box extends from the lower to upper quartiles. The middle line represents the median value. $\mathrm{X}$ indicates the mean value. The whiskers represent the minimum to maximum values, except for outliers, which are indicated by dots. $\mathrm{n}=33 .{ }^{* *} \mathrm{P}<0.01$ vs. DMSO. (C) LysoTracker staining (magenta) $1 \mathrm{~h}$ after treatment with Lap (10 $\left.\mu \mathrm{M}\right)$ and HCQ (50 $\left.\mu \mathrm{M}\right)$ in BxPC-3 cells. Scale bar, $20 \mu \mathrm{m}$. (D) Relative mean fluorescence intensities of LysoTracker in each condition of BxPC-3 cells from (C) are shown. Data were analyzed using Mann Whitney $U$ test. The box extends from the lower to upper quartiles. The middle line represents the median value. $\mathrm{X}$ indicates the mean value. The whiskers represent the minimum to maximum values, except for outliers, which are indicated by dots. $\mathrm{n}=32$. ${ }^{* *} \mathrm{P}<0.01 \mathrm{vs}$. DMSO. (E) Immunofluorescence analysis of LAMP2 (magenta) and LGALS3 (green) $10 \mathrm{~h}$ after treatment with Lap $(10 \mu \mathrm{M})$ and Abe $(10 \mu \mathrm{M})$ in BxPC-3 cells. The dashed boxed regions are shown at high magnification at the bottom. Scale bar, $20 \mu \mathrm{m}$. (F) Colocalization of fluorescence between LGALS3 and LAMP2 in BxPC-3 cells from (E) was analyzed using ImageJ. Data were analyzed using Mann Whitney U test. The box extends from the lower to upper quartiles. The middle line represents the median value. X indicates the mean value. The whiskers represent the minimum to maximum values, except for outliers, which are indicated by dots. $\mathrm{n}=76 .{ }^{* *} \mathrm{P}<0.01 \mathrm{vs}$. $\mathrm{DMSO}$. (G) Immunofluorescence analysis of LAMP2 (magenta) and LGALS3 (green) $10 \mathrm{~h}$ after treatment with Lap (10 $\mu \mathrm{M})$ and HCQ (50 $\mu \mathrm{M})$ in BxPC-3 cells. The dashed boxed regions are shown at high magnification at the bottom. Scale bar, $20 \mu \mathrm{m}$. (H) The colocalization of fluorescence between LGALS3 and LAMP2 in BxPC-3 cells from (G) was analyzed using ImageJ. Data were analyzed using Mann Whitney U test. The box extends from the lower to upper quartiles. The middle line represents the median value. $\mathrm{X}$ indicates the mean value. The whiskers represent the minimum to maximum values, except for outliers, which are indicated by dots. $\mathrm{n}=92{ }^{*}{ }^{* *} \mathrm{P}<0.01$ vs. DMSO. (I) Intracellular $\mathrm{Ca}^{2+}$ concentrations were assessed $1 \mathrm{~h}$ after combination treatment with Lap (10 $\left.\mu \mathrm{M}\right)$ and Abe $(10 \mu \mathrm{M})$ in BxPC-3 cells using Fluo-8-AM (green). Scale bar, $50 \mu \mathrm{m}$. (J) Relative mean fluorescence intensities of Fluo-8-AM in BxPC-3 cells from (I) are presented. Data were analyzed using an unpaired two-tailed Student's t-test. Data are presented as the mean \pm standard deviation, $\mathrm{n}=18$. ${ }^{* *} \mathrm{P}<0.01$ vs. DMSO. (K) Intracellular $\mathrm{Ca}^{2+}$ concentrations were assessed $1 \mathrm{~h}$ after combination treatment with Lap (10 $\left.\mu \mathrm{M}\right)$ and $\mathrm{HCQ}(50 \mu \mathrm{M})$ in BxPC-3 cells using Fluo-8-AM (green). Scale bar, $50 \mu \mathrm{m}$. (L) Relative mean fluorescence intensities of Fluo-8-AM in BxPC-3 cells from (K) are presented. Data were analyzed using an unpaired two-tailed Student's t-test. Data are presented as the mean $\pm \mathrm{SD}, \mathrm{n}=12 .{ }^{* *} \mathrm{P}<0.01$ vs. DMSO. Lap, lapatinib; Abe, abemaciclib; DMSO, dimethyl sulfoxide; HCQ, hydroxychloroquine; LAMP2, lysosome-associated membrane protein 2; LGALS3, galectin-3; Ca ${ }^{2+}$, calcium.

treatment with lapatinib and FTY720 and failed to suppress the growth inhibitory effect of the combination treatment (Fig. S12E-G). In KP-4 cells, U18666A suppressed the increased intracellular $\mathrm{Ca}^{2+}$ concentration and mitochondrial depolarization after combination treatment with lapatinib and FTY720 (Fig. 10C-F). Additionally, real-time ER stress 
A

DMSO
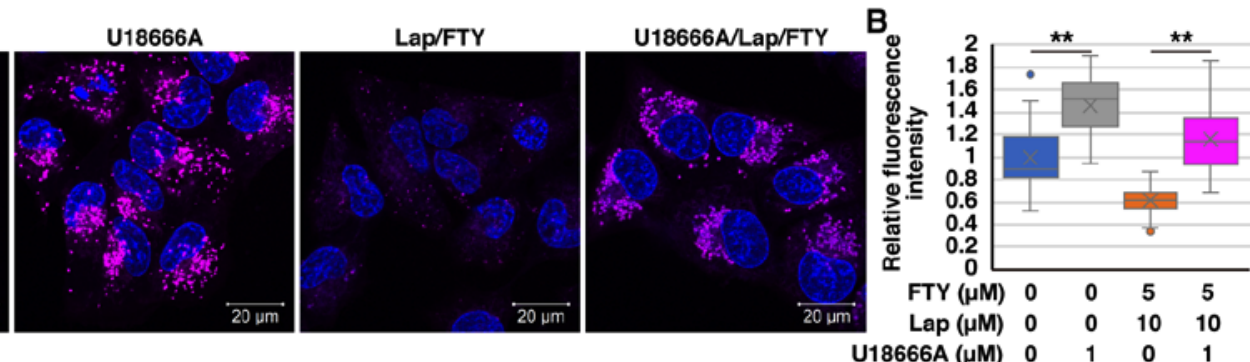

C

LysoTracker/Hoechst
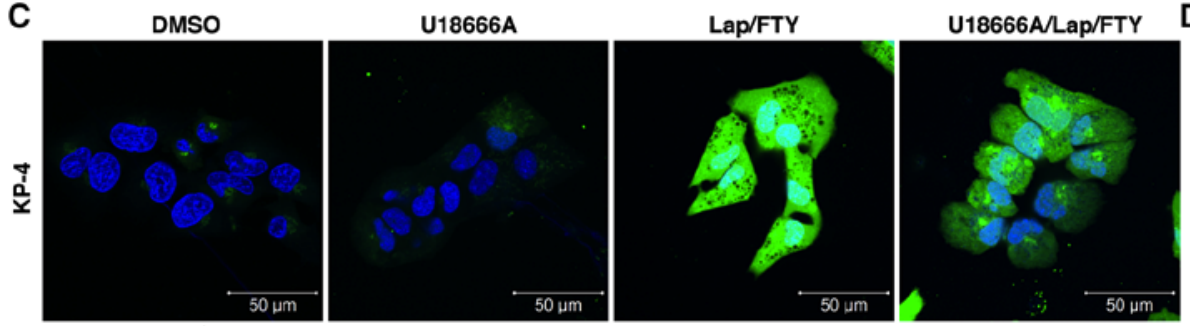

$\begin{array}{lllll}\mathrm{U} 18666 \mathrm{~A}(\mu \mathrm{M}) & 0 & 1 & 0 & 1\end{array}$
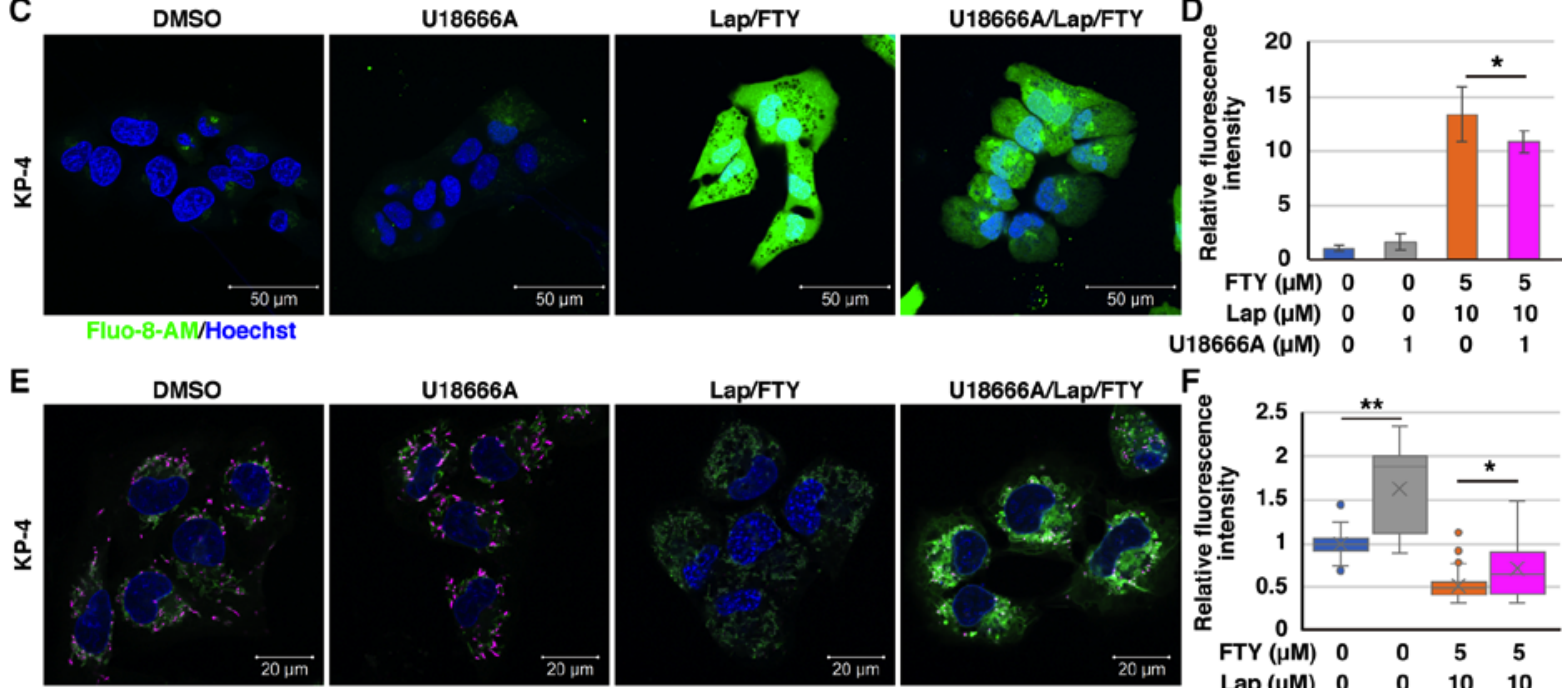

JC1poly/JC1mono/Hoechst

G

PANC-1

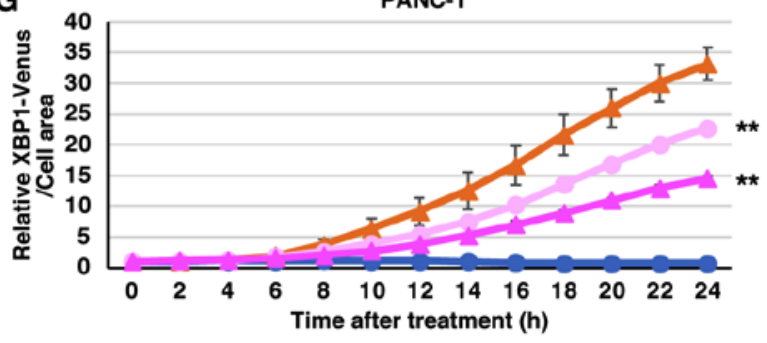

H

KP-4

I

$F$

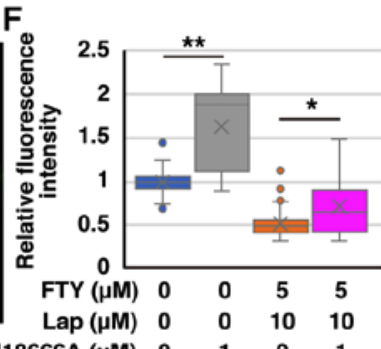

U18666A $(\mu \mathrm{M}) \quad 0 \quad 1 \quad 0 \quad 1$

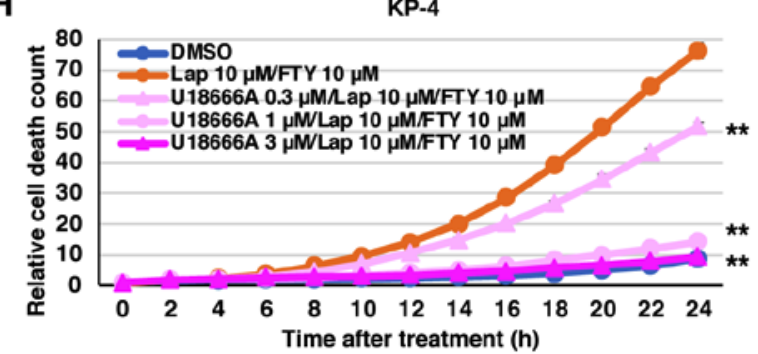

PANC-1

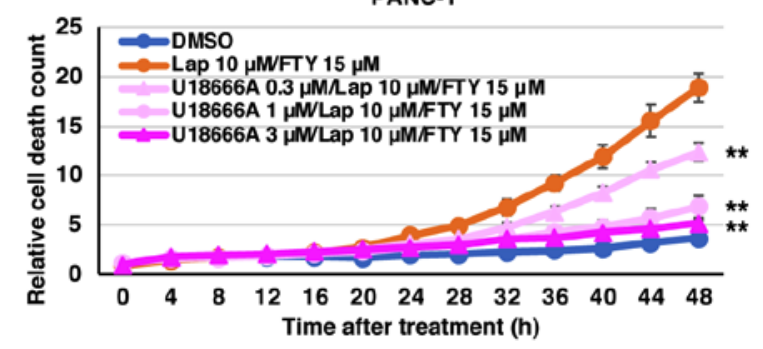

Figure 10. U18666A mitigates the effects of combination treatment with Lap and FTY in pancreatic ductal adenocarcinoma cells. (A) LysoTracker staining (magenta) $1 \mathrm{~h}$ after treatment with Lap $(10 \mu \mathrm{M})$ and FTY $(5 \mu \mathrm{M})$ in the presence $(1 \mu \mathrm{M})$ or absence of U18666A in KP- 4 cells. Scale bar, $20 \mu \mathrm{m}$. (B) Relative mean fluorescence intensities of LysoTracker in each condition of KP-4 cells from (A) are shown. Data were analyzed using Kruskal-Wallis with Dunn's post hoc test. The box extends from the lower to upper quartiles. The middle line represents the median value. $\mathrm{X}$ indicates the mean value. The whiskers represent the minimum to maximum values, except for outliers, which are indicated by dots. $\mathrm{n}=23$. ${ }^{* *} \mathrm{P}<0.01$ vs. U18666A $0 \mu \mathrm{M}$. (C) Intracellular Ca ${ }^{2+}$ concentrations were assessed $1 \mathrm{~h}$ after treatment with Lap $(10 \mu \mathrm{M})$ and FTY $(5 \mu \mathrm{M})$ in the presence $(1 \mu \mathrm{M})$ or absence of U18666A in KP-4 cells using Fluo-8-AM (green). Scale bar, $50 \mu \mathrm{m}$. (D) Relative mean fluorescence intensities of Fluo-8-AM in KP-4 cells from (C) are presented. Data were analyzed using one-way ANOVA followed by Tukey's post hoc test. Data are presented as the mean \pm standard deviation, $\mathrm{n}=6$. $\mathrm{P}<0.05$ vs. U18666A $0 \mu \mathrm{M}$. (E) Mitochondrial membrane potential was assessed $1 \mathrm{~h}$ after treatment with Lap $(10 \mu \mathrm{M})$ and FTY $(5 \mu \mathrm{M})$ in the presence $(1 \mu \mathrm{M})$ or absence of U18666A in KP-4 cells using JC-1 (magenta and green). Scale bar, $20 \mu \mathrm{m}$. (F) Relative mean fluorescence intensities (magenta/green) of JC-1 in KP-4 cells from (E) are presented. Data were analyzed using Kruskal-Wallis with Dunn's post hoc test. The box extends from the lower to upper quartiles. The middle line represents the median value. $\mathrm{X}$ indicates the mean value. The whiskers represent the minimum to maximum values, except for outliers, which are indicated by dots. $n=32$. ${ }^{P} \mathrm{P}<0.05$ and ${ }^{* *} \mathrm{P}<0.01 \mathrm{vs}$. U18666A $0 \mu \mathrm{M}$. (G) PANC-1/XBP1-Venus cells were treated with Lap $(10 \mu \mathrm{M})$ and FTY $(15 \mu \mathrm{M})$ in the presence $(1$ or $3 \mu \mathrm{M})$ or absence of U18666A. The fluorescence intensities derived from XBP1-Venus were monitored over $24 \mathrm{~h}$. Data were analyzed using two-way ANOVA followed by Bonferroni's post hoc test. Data are presented as the mean \pm standard deviation, $\mathrm{n}=4 .{ }^{* *} \mathrm{P}<0.01$ vs. Lap $10 \mu \mathrm{M} / \mathrm{FTY} 15 \mu \mathrm{M}$. (H and I) The PI fluorescence intensity obtained from dead cells was monitored following combination treatment with Lap and FTY in the presence $(0.3,1$ or $3 \mu \mathrm{M})$ or absence of U18666A in (H) KP-4 and (I) PANC-1 cells. Data were analyzed using two-way ANOVA followed by Bonferroni's post hoc test. Data are presented as the mean \pm standard deviation, $\mathrm{n}=4$. $(\mathrm{H}){ }^{* * *} \mathrm{P}<0.01 \mathrm{vs}$. Lap $10 \mu \mathrm{M} / \mathrm{FTY} 10 \mu \mathrm{M}$, (I) *** P<0.01 vs. Lap $10 \mu \mathrm{M} / \mathrm{FTY} 15 \mu \mathrm{M}$. Lap, lapatinib; FTY, FTY720; DMSO, dimethyl sulfoxide; $\mathrm{Ca}^{2+}$, calcium. 
monitoring analysis revealed that U18666A suppressed the increase in ER stress after combination treatment with lapatinib and FTY720 in PANC-1 cells (Fig. 10G). Furthermore, U18666A effectively suppressed cell death induced by combination treatment with lapatinib and FTY720 in PDAC cells (Figs. $10 \mathrm{H}$ and $\mathrm{I}$ and $\mathrm{S} 12 \mathrm{H}$ ). These results suggested that the combination of lysosome-targeted drugs induces mitochondrial and ER dysfunction and non-canonical death in PDAC cells, at least in part, directly due to lysosomal dysfunction (Fig. S13).

\section{Discussion}

In the present study, the findings revealed that FTY720, an FDA-approved drug for multiple sclerosis, could enhance the cytotoxic effect of lapatinib in various PDAC cell lines. Apoptosis, necroptosis and autophagic cell death were not determined as major factors mediating cell death induced by combination treatment with lapatinib and FTY720 in PDAC cells, albeit with partial contributions. Furthermore, ROS involvement in cell death depended on the examined cell line and was not considered a common key factor. Combination treatment with lapatinib and FTY720 enhanced LMP, subsequently inducing mitochondrial depolarization, ER stress and DNA damage, thus resulting in non-canonical death in PDAC cells. The enhanced cytotoxic effect of lapatinib on PDAC cells was exerted in combination with FTY720, abemaciclib or HCQ, indicating that a lysosome-targeted drug combination could be a useful therapeutic strategy against pancreatic cancer. However, although the combined effect of lapatinib and FTY720 was antagonistic in the non-cancerous cell line LP101, its effect on normal cells needs to be verified in an in vivo animal model.

Cationic amphiphilic drugs, known to contain a basic moiety, exhibit lysosomotropism and accumulate within lysosomes after drug protonation, often leading to LMP and lysosomal dysfunction (63-66). Lapatinib has been identified as a lysosomotropic compound using a high-content screening assay (36). NBD-FTY720, a fluorescently labeled FTY720 analog, has been shown to be mainly trapped in the lysosomes of U251MG human glioma cells (28). Abemaciclib has been reported to behave similarly to palbociclib, which can be trapped in the lysosomes of SK-Mel-103 human melanoma cells (67). Previously, we reported that FTY720 impairs lysosomal function in NSCLC cells (18), and in the present study, combination treatment with lapatinib and FTY720 induced LMP in PDAC cells. LMP results in the leakage of lysosomal content into the cytosol, causing so-called 'lysosome-dependent cell death' $(51,68)$. Lysosome-dependent cell death is primarily mediated by lysosomal hydrolases, such as cathepsin proteases $(51,68)$. In the current study, cell death induced by combination treatment with lapatinib and FTY720 was not repressed by E64d, an inhibitor of cysteine proteases, such as cathepsin B and cathepsin L, and pepstatin A, an inhibitor of aspartic proteases, such as cathepsin D, cathepsin E and pepsin. Additionally, combination treatment suppressed the expression and maturation of cathepsin B. Accordingly, these findings indicated that cell death induced by combination treatment with lapatinib and FTY720 cannot be attributed to LMP-induced proteolytic enzyme leakage from the lysosome.
In addition, lysosomes, ER and mitochondria serve as intracellular $\mathrm{Ca}^{2+}$ stores, while cytosolic $\mathrm{Ca}^{2+}$ concentrations are maintained at low concentrations $(52,69-71)$. Therefore, $\mathrm{Ca}^{2+}$ sequestered in lysosomes leaks out of lysosomes owing to LMP (51). In the present study, combination treatment with lapatinib and FTY720 increased the intracellular $\mathrm{Ca}^{2+}$ concentration. Calpains, cytosolic $\mathrm{Ca}^{2+}$-activated neutral proteases, are reportedly activated by LMP and are known to be involved in the degradation of several lysosomal proteins, including HSP70.1 and LAMP2 (72,73). These enzymes may also play a role in cell death mediated by combination treatment with lapatinib and FTY720. Moreover, intimate and dynamic communication occurs between intracellular organelles via membrane contact sites $(74,75) . \mathrm{Ca}^{2+}$ release and influx are regulated between lysosomes, ER and mitochondria via their respective channels, and intracellular $\mathrm{Ca}^{2+}$ homeostasis is maintained in conjunction with extracellular $\mathrm{Ca}^{2+}$ entry $(52,71)$. Therefore, LMP-induced $\mathrm{Ca}^{2+}$ leakage from lysosomes also affects $\mathrm{Ca}^{2+}$ regulation in the ER and mitochondria, resulting in ER stress and mitochondrial depolarization; $\mathrm{Ca}^{2+}$ may be the key regulatory factor mediating cell death induced by combination treatment with lapatinib and FTY720. However, the increased intracellular $\mathrm{Ca}^{2+}$ concentration can be, at least in part, directly attributed to lysosomal leakage; however, the role of leakage from mitochondria, ER and extracellular influx needs to be investigated in future investigations.

FTY720 is a sphingosine analog that reportedly inhibits sphingosine kinase 1 (76), sphingosine-1-phosphate lyase 1 (77), ceramide synthases $(78,79)$ and lysosomal acid sphingomyelinase (80), all enzymes involved in sphingolipid metabolism. FTY720 suppresses these enzymatic activities at micromolar concentrations, thus altering intracellular sphingolipid metabolism (81). De novo synthesis of sphingolipids occurs in the ER, and the formed ceramide is transported to the Golgi, further modified, and transported to other membrane compartments, including the plasma membrane, lysosomes and mitochondria $(82,83)$. In the present study, combination treatment with lapatinib and FTY720 rapidly induced LMP in lysosomes, and ER stress loading was observed as a subsequent response. In addition, PDAC cell death was not only induced by the combination of lapatinib and FTY720, but also by combining lapatinib and abemaciclib or lapatinib and HCQ. Therefore, the direct action of FTY720 on the ER, the site of sphingolipid synthesis, cannot be completely excluded; the contribution of suppressed sphingolipid metabolism on cell death induction is considered adjunctive, if any.

Several additional factors must be considered. First, the combination of lysosome-targeted drugs, i.e., lapatinib, FTY720, HCQ and abemaciclib, showed remarkable cytotoxic effects in multiple pancreatic cancer cell lines. However, direct molecules targeted by each drug, as well as cell death executing molecules, mediating the pronounced cytotoxic effect of combination drug treatment remain to be elucidated, and future studies are needed to clarify the underlying downstream mediators. In addition to clarifying the effects of these drugs on autophagic flux in the present study, it is necessary to analyze the effects on the macropinocytosis pathway and evaluate the role of inhibiting these pathways on cell death induction. Second, KRAS mutant PANC-1, MIA PaCa-2, KP-4, KP-3 and KP-2 cells and KRAS wild-type BxPC-3 cells were used, and it was revealed that 
combination treatment with lapatinib and FTY720 was effective in all cell lines, regardless of $K R A S$ mutation. However, to date, gene mutations have been poorly investigated. Therefore, it is necessary to further analyze the association between combined effects and gene mutations in KRAS, p16/CDKN2A, p53/TP53 and $S M A D 4$, which are frequently mutated in pancreatic cancer cells $(2,84)$. Third, the present study only performed in vitro analyses, and investigations using animal models and clinically derived samples should be undertaken in the future to confirm these effects in vivo.

In conclusion, the combination of lapatinib and FTY720 demonstrated significant effects on PDAC cells, suggesting its ability to improve the efficacy of combination chemotherapy in patients with PDAC. HCQ and abemaciclib are also useful candidates for improving treatment options in combination with lapatinib. Lapatinib, FTY720, HCQ and abemaciclib are all FDA-approved drugs whose safety and toxicity have been previously determined. Therefore, the present study has the potential to rapidly improve the treatment of patients with PDAC. Although lysosome-targeted drug combinations are markedly efficacious, their underlying molecular mechanisms need to be further elucidated to achieve evidence-based medicine.

\section{Acknowledgements}

The authors would like to thank Dr A. Abe and Mr. S. Moriya (Department of Biochemistry, Tokyo Medical University, Japan) and Dr H. Hino (Division of Anatomical Science, Department of Functional Morphology, Nihon University School of Medicine, Japan) for their technical assistance.

\section{Funding}

This study was supported by the Japan Society for the Promotion of Science KAKENHI (grant nos. 18K06901 and 21K07106), the MEXT-Supported Program of the Strategic Research Foundation at Private Universities (grant no. S1411011 and 2014e2018), from the Ministry of Education, Culture, Sports, Science and Technology of Japan, and the Cancer Research Grant afforded by the Tokyo Medical University Cancer Research Foundation (2021).

\section{Availability of data and materials}

The datasets used and/or analyzed during the current study are available from the corresponding author on reasonable request.

\section{Authors' contributions}

MH, SS, MO and KM designed the study. SS, MO, MM, KO, $\mathrm{HK}, \mathrm{AH}, \mathrm{NT}$ and $\mathrm{MH}$ performed the experiments and analyzed the data. SS, MO and MH confirm the authenticity of the raw data. $\mathrm{MH}, \mathrm{SS}, \mathrm{MO}, \mathrm{NT}$ and KM were major contributors to writing the manuscript. All authors have read and approved the final manuscript.

\section{Ethics approval and consent to participate}

Not applicable.

\section{Patent consent for publication}

Not applicable.

\section{Competing interests}

The authors declare that they have no competing interests.

\section{References}

1. Rawla P, Sunkara T and Gaduputi V: Epidemiology of pancreatic cancer: Global trends, etiology and risk factors. World J Oncol 10: 10-27, 2019.

2. Mizrahi JD, Surana R, Valle JW and Shroff RT: Pancreatic cancer. Lancet 395: 2008-2020, 2020.

3. Ushio J, Kanno A, Ikeda E, Ando K, Nagai H, Miwata T, Kawasaki Y, Tada Y, Yokoyama K, Numao N, et al: Pancreatic ductal adenocarcinoma: Epidemiology and risk factors. Diagnostics (Basel) 11: 562, 2021.

4. Rai V and Agrawal S: Targets (metabolic mediators) of therapeutic importance in pancreatic ductal adenocarcinoma. Int J Mol Sci 21: 8502, 2020

5. Feig C, Gopinathan A, Neesse A, Chan DS, Cook N and Tuveson DA: The pancreas cancer microenvironment. Clin Cancer Res 18: 4266-4276, 2012.

6. Conroy T, Desseigne F, Ychou M, Bouché O, Guimbaud R, Bécouarn Y, Adenis A, Raoul JL, Gourgou-Bourgade S, de la Fouchardière $\mathrm{C}$, et al: FOLFIRINOX versus gemcitabine for metastatic pancreatic cancer. N Engl J Med 364: 1817-1825, 2011.

7. Suker M, Beumer BR, Sadot E, Marthey L, Faris JE, Mellon EA, El-Rayes BF, Wang-Gillam A, Lacy J, Hosein PJ, et al: FOLFIRINOX for locally advanced pancreatic cancer: A systematic review and patient-level meta-analysis. Lancet Oncol 17: 801-810, 2016.

8. Zeng S, Pöttler M, Lan B, Grützmann R, Pilarsky C and Yang H: Chemoresistance in pancreatic cancer. Int J Mol Sci 20: 4504 , 2019.

9. Florey $\mathrm{O}$ and Overholtzer M: Macropinocytosis and autophagy crosstalk in nutrient scavenging. Philos Trans R Soc Lond B Biol Sci 374: 20180154, 2019.

10. Bryant KL, Mancias JD, Kimmelman AC and Der CJ: KRAS: Feeding pancreatic cancer proliferation. Trends Biochem Sci 39: 91-100, 2014.

11. Piffoux M, Eriau E and Cassier PA: Autophagy as a therapeutic target in pancreatic cancer. Br J Cancer 124: 333-344, 2021.

12. Su H, Yang F, Fu R, Li X, French R, Mose E, Pu X, Trinh B, Kumar A, Liu J, et al: Cancer cells escape autophagy inhibition via NRF2-induced macropinocytosis. Cancer Cell 39: 678-693. e11, 2021.

13. Morishita $\mathrm{H}$ and Mizushima $\mathrm{N}$ : Diverse cellular roles of autophagy. Annu Rev Cell Dev Biol 35: 453-475, 2019.

14. Sousa CM, Biancur DE, Wang X, Halbrook CJ, Sherman MH, Zhang L, Kremer D, Hwang RF, Witkiewicz AK, Ying H, et al: Pancreatic stellate cells support tumour metabolism through autophagic alanine secretion. Nature 536: 479-483, 2016.

15. Recouvreux MV and Commisso C: Macropinocytosis: A metabolic adaptation to nutrient stress in cancer. Front Endocrinol (Lausanne) 8: 261, 2017.

16. Perera RM and Zoncu R: The lysosome as a regulatory Hub. Annu Rev Cell Dev Biol 32: 223-253, 2016.

17. Gupta S, Yano J, Mercier V, Htwe HH, Shin HR, Rademaker G, Cakir Z, Ituarte T, Wen KW, Kim GE, et al: Lysosomal retargeting of myoferlin mitigates membrane stress to enable pancreatic cancer growth. Nat Cell Biol 23: 232-242, 2021.

18. Ota K, Okuma T, Lorenzo A, Yokota A, Hino H, Kazama H, Moriya S, Takano N, Hiramoto M and Miyazawa K: Fingolimod sensitizes EGFR wild-type non-small cell lung cancer cells to lapatinib or sorafenib and induces cell cycle arrest. Oncol Rep 42: 231-242, 2019.

19. Zhang N, Qi Y, Wadham C, Wang L, Warren A, Di W and Xia P: FTY720 induces necrotic cell death and autophagy in ovarian cancer cells: A protective role of autophagy. Autophagy 6: 1157-1167, 2010.

20. Liao A, Hu R, Zhao Q, Li J, Li Y, Yao K, Zhang R, Wang H, Yang W and Liu Z: Autophagy induced by FTY720 promotes apoptosis in U266 cells. Eur J Pharm Sci 45: 600-605, 2012. 
21. Zhang L, Wang H, Ding $\mathrm{K}$ and Xu J: FTY720 induces autophagy-related apoptosis and necroptosis in human glioblastoma cells. Toxicol Lett 236: 43-59, 2015.

22. Li J, Wang SW, Zhang DS, Sun Y, Zhu CY, Fei Q, Hu J, Zhang C and Sun YM: FTY720-induced enhancement of autophagy protects cells from FTY720 cytotoxicity in colorectal cancer. Oncol Rep 35: 2833-2842, 2016.

23. Alinari L, Mahoney E, Patton J, Zhang X, Huynh L, Earl CT, Mani R, Mao Y, Yu B, Quinion C, et al: FTY720 increases CD74 expression and sensitizes mantle cell lymphoma cells to milatuzumab-mediated cell death. Blood 118: 6893-6903, 2011.

24. Trkov S, Stenovec M, Kreft M, Potokar M, Parpura V, Davletov B and Zorec R: Fingolimod-a sphingosine-like molecule inhibits vesicle mobility and secretion in astrocytes. Glia 60: 1406-1416, 2012.

25. Ahmed D, de Verdier PJ, Ryk C, Lunqe O, Stål P and Flygare J: FTY720 (Fingolimod) sensitizes hepatocellular carcinoma cells to sorafenib-mediated cytotoxicity. Pharmacol Res Perspect 3 : $\mathrm{e} 00171,2015$

26. Tay KH, Liu X, Chi M, Jin L, Jiang CC, Guo ST, Verrills NM, Tseng HY and Zhang XD: Involvement of vacuolar H(+)-ATPase in killing of human melanoma cells by the sphingosine kinase analogue FTY720. Pigment Cell Melanoma Res 28: 171-183, 2015.

27. Li X, Wang MH, Qin C, Fan WH, Tian DS and Liu JL: Fingolimod suppresses neuronal autophagy through the mTOR/p70S6K pathway and alleviates ischemic brain damage in mice. PLoS One 12: e0188748, 2017.

28. Min KJ and Kwon TK: Induction of lysosomal membrane permeabilization is a major event of FTY720-mediated non-apoptotic cell death in human glioma cells. Cancers (Basel) 12: 3388 2020 .

29. Aizawa S, Yaguchi M, Nakano M, Toyama K, Inokuchi S, Imai T, Yasuda M, Nabeshima R and Handa H: Hematopoietic supportive function of human bone marrow stromal cell lines established by a recombinant SV40-adenovirus vector. Exp Hematol 22: 482-487, 1994.

30. Kazama H, Hiramoto M, Miyahara K, Takano N and Miyazawa K Designing an effective drug combination for ER stress loading in cancer therapy using a real-time monitoring system. Biochem Biophys Res Commun 501: 286-292, 2018.

31. Iwawaki T, Akai R, Kohno K and Miura M: A transgenic mouse model for monitoring endoplasmic reticulum stress. Nat Med 10: 98-102, 2004.

32. Kaizuka T, Morishita H, Hama Y, Tsukamoto S, Matsui T, Toyota Y, Kodama A, Ishihara T, Mizushima T and Mizushima N An autophagic flux probe that releases an internal control. Mol Cell 64: 835-849, 2016

33. Saito Y,Moriya S, Kazama H,HirasawaK, MiyaharaK, KokubaH, Hino H, Kikuchi H, Takano N, Hiramoto M, et al: Amino acid starvation culture condition sensitizes EGFR-expressing cancer cell lines to gefitinib-mediated cytotoxicity by inducing atypical necroptosis. Int J Oncol 52: 1165-1177, 2018.

34. Livak KJ and Schmittgen TD: Analysis of relative gene expression data using real-time quantitative PCR and the 2(-Delta Delta C(T)) method. Methods 25: 402-408, 2001.

35. Aizawa S, Hiramoto M, Hoshi H, Toyama K, Shima D and Handa H: Establishment of stromal cell line from an MDS RA patient which induced an apoptotic change in hematopoietic and leukemic cells in vitro. Exp Hematol 28: 148-155, 2000.

36. Nadanaciva S, Lu S, Gebhard DF, Jessen BA, Pennie WD and Will Y: A high content screening assay for identifying lysosomotropic compounds. Toxicol In Vitro 25: 715-723, 2011

37. Chou TC: Theoretical basis, experimental design, and computerized simulation of synergism and antagonism in drug combination studies. Pharmacol Rev 58: 621-681, 2006.

38. Chiba K, Kataoka H, Seki N, Shimano K, Koyama M, Fukunari A, Sugahara K and Sugita T: Fingolimod (FTY720), sphingosine 1-phosphate receptor modulator, shows superior efficacy as compared with interferon- $\beta$ in mouse experimental autoimmune encephalomyelitis. Int Immunopharmacol 11 : 366-372, 2011

39. White C, Alshaker H, Cooper C, Winkler M and Pchejetski D: The emerging role of FTY720 (fingolimod) in cancer treatment. Oncotarget 7: 23106-23127, 2016.

40. Heymach JV,Nilsson M,Blumenschein G,Papadimitrakopoulou V and Herbst R: Epidermal growth factor receptor inhibitors in development for the treatment of non-small cell lung cancer. Clin Cancer Res 12: 4441s-4445s, 2006.
41. Legrand C, Bour JM, Jacob C, Capiaumont J, Martial A, Marc A, Wudtke M, Kretzmer G, Demangel C, Duval D, et al: Lactate dehydrogenase (LDH) activity of the cultured eukaryotic cells as marker of the number of dead cells in the medium [corrected] J Biotechnol 25: 231-243, 1992

42. Crowley LC, Marfell BJ, Scott AP and Waterhouse NJ: Quantitation of apoptosis and necrosis by annexin V binding, propidium iodide uptake, and flow cytometry. Cold Spring Harb Protoc 2016, 2016.

43. Duriez PJ and Shah GM: Cleavage of poly(ADP-ribose) polymerase: A sensitive parameter to study cell death. Biochem Cell Biol 75: 337-349, 1997.

44. Rogakou EP, Boon C, Redon C and Bonner WM: Megabase chromatin domains involved in DNA double-strand breaks in vivo. J Cell Biol 146: 905-916, 1999.

45. Rogakou EP, Nieves-Neira W, Boon C, Pommier Y and Bonner WM: Initiation of DNA fragmentation during apoptosis induces phosphorylation of $\mathrm{H} 2 \mathrm{AX}$ histone at serine 139. J Biol Chem 275: 9390-9395, 2000

46. Patel T, Gores GJ and Kaufmann SH: The role of proteases during apoptosis. FASEB J 10: 587-597, 1996.

47. Degterev A, Hitomi J, Germscheid M, Ch'en IL, Korkina O, Teng X, Abbott D, Cuny GD, Yuan C, Wagner G, et al: Identification of RIP1 kinase as a specific cellular target of necrostatins. Nat Chem Biol 4: 313-321, 2008.

48. Aruoma OI, Halliwell B, Hoey BM and Butler J: The antioxidant action of $\mathrm{N}$-acetylcysteine: Its reaction with hydrogen peroxide, hydroxyl radical, superoxide, and hypochlorous acid. Free Radic Biol Med 6: 593-597, 1989.

49. Wu YT, Tan HL, Huang Q, Kim YS, Pan N, Ong WY, Liu ZG, Ong $\mathrm{CN}$ and Shen HM: Autophagy plays a protective role during zVAD-induced necrotic cell death. Autophagy 4: 457-466, 2008.

50. Wang F, Gómez-Sintes R and Boya P: Lysosomal membrane permeabilization and cell death. Traffic 19: 918-931, 2018.

51. Serrano-Puebla A and Boya P: Lysosomal membrane permeabilization as a cell death mechanism in cancer cells. Biochem Soc Trans 46: 207-215, 2018.

52. Cremer T, Neefjes J and Berlin I: The journey of $\mathrm{Ca}^{2+}$ through the cell-pulsing through the network of ER membrane contact sites. J Cell Sci 133: jcs249136, 2020.

53. Lemasters JJ, Nieminen AL, Qian T, Trost LC, Elmore SP, Nishimura Y, Crowe RA, Cascio WE, Bradham CA, Brenner DA and Herman B: The mitochondrial permeability transition in cell death: A common mechanism in necrosis, apoptosis and autophagy. Biochim Biophys Acta 1366: 177-196, 1998.

54. Kim I, Rodriguez-Enriquez S and Lemasters JJ: Selective degradation of mitochondria by mitophagy. Arch Biochem Biophys 462: 245-253, 2007.

55. Ponnambalam S, Girotti M, Yaspo ML, Owen CE, Perry AC, Suganuma T, Nilsson T, Fried M, Banting G and Warren G: Primate homologues of rat TGN38: Primary structure, expression and functional implications. J Cell Sci 109: 675-685, 1996.

56. Ghosh RN, Mallet WG, Soe TT, McGraw TE and Maxfield FR: An endocytosed TGN38 chimeric protein is delivered to the TGN after trafficking through the endocytic recycling compartment in CHO cells. J Cell Biol 142: 923-936, 1998.

57. Di Martino R, Sticco L and Luini A: Regulation of cargo export and sorting at the trans-Golgi network. FEBS Lett 593: 2306-2318, 2019

58. Hino H, Iriyama N, Kokuba H, Kazama H, Moriya S, Takano N, Hiramoto M, Aizawa S and Miyazawa K: Abemaciclib induces atypical cell death in cancer cells characterized by formation of cytoplasmic vacuoles derived from lysosomes. Cancer Sci 111: 2132-2145, 2020.

59. Ohkuma S and Poole B: Fluorescence probe measurement of the intralysosomal $\mathrm{pH}$ in living cells and the perturbation of $\mathrm{pH}$ by various agents. Proc Natl Acad Sci USA 75: 3327-3331, 1978.

60. Mackenzie AH: Pharmacologic actions of 4-aminoquinoline compounds. Am J Med 75: 5-10, 1983.

61. Appelqvist H, Nilsson C, Garner B, Brown AJ, Kagedal K and Ollinger K: Attenuation of the lysosomal death pathway by lysosomal cholesterol accumulation. Am J Pathol 178: 629-639, 2011.

62. Appelqvist H, Sandin L, Björnström K, Saftig P, Garner B, Ollinger K and Kågedal K: Sensitivity to lysosome-dependent cell death is directly regulated by lysosomal cholesterol content. PLoS One 7: e50262, 2012.

63. Kornhuber J, Henkel AW, Groemer TW, Städtler S, Welzel O, Tripal P, Rotter A, Bleich S and Trapp S: Lipophilic cationic drugs increase the permeability of lysosomal membranes in a cell culture system. J Cell Physiol 224: 152-164, 2010. 
64. Villamil Giraldo AM, Appelqvist H, Ederth T and Öllinger K Lysosomotropic agents: Impact on lysosomal membrane permeabilization and cell death. Biochem Soc Trans 42: 1460-1464, 2014

65. Lu S, Sung T, Lin N, Abraham RT and Jessen BA: Lysosomal adaptation: How cells respond to lysosomotropic compounds. PLoS One 12: e0173771, 2017.

66. Anand A, Liu B, Dicroce Giacobini J, Maeda K, Rohde M and Jäättelä M: Cell death induced by cationic amphiphilic drugs depends on lysosomal $\mathrm{Ca}^{2+}$ release and cyclic AMP. Mol Cancer Ther 18: 1602-1614, 2019.

67. Llanos S, Megias D, Blanco-Aparicio C, Hernández-Encinas E, Rovira M, Pietrocola F and Serrano M: Lysosomal trapping of palbociclib and its functional implications. Oncogene 38 : 3886-3902, 2019.

68. Aits S and Jäättelä M: Lysosomal cell death at a glance. J Cell Sci 126: 1905-1912, 2013.

69. Xu H and Ren D: Lysosomal physiology. Annu Rev Physiol 77: 57-80, 2015.

70. Ballabio A and Bonifacino JS: Lysosomes as dynamic regulators of cell and organismal homeostasis. Nat Rev Mol Cell Biol 21: 101-118, 2020.

71. Wu Y, Huang P and Dong XP: Lysosomal calcium channels in autophagy and cancer. Cancers (Basel) 13: 1299, 2021.

72. Sahara S and Yamashima T: Calpain-mediated Hsp70.1 cleavage in hippocampal CA1 neuronal death. Biochem Biophys Res Commun 393: 806-811, 2010.

73. Villalpando Rodriguez GE and Torriglia A: Calpain 1 induce lysosomal permeabilization by cleavage of lysosomal associated membrane protein 2. Biochim Biophys Acta 1833: 2244-2253, 2013.

74. Phillips MJ and Voeltz GK: Structure and function of ER membrane contact sites with other organelles. Nat Rev Mol Cell Biol 17: 69-82, 2015.

75. Prinz WA, Toulmay A and Balla T: The functional universe of membrane contact sites. Nat Rev Mol Cell Biol 21: 7-24, 2020.
76. Vessey DA, Kelley M, Zhang J, Li L, Tao R and Karliner JS: Dimethylsphingosine and FTY720 inhibit the SK1 form but activate the SK2 form of sphingosine kinase from rat heart. J Biochem Mol Toxicol 21: 273-279, 2007.

77. Bandhuvula P, Tam YY, Oskouian B and Saba JD: The immune modulator FTY720 inhibits sphingosine-1-phosphate lyase activity. J Biol Chem 280: 33697-33700, 2005.

78. Berdyshev EV, Gorshkova I, Skobeleva A, Bittman R, Lu X, Dudek SM, Mirzapoiazova T, Garcia JG and Natarajan V: FTY720 inhibits ceramide synthases and up-regulates dihydrosphingosine 1-phosphate formation in human lung endothelial cells. J Biol Chem 284: 5467-5477, 2009.

79. Lahiri S, Park H, Laviad EL, Lu X, Bittman R and Futerman AH: Ceramide synthesis is modulated by the sphingosine analog FTY720 via a mixture of uncompetitive and noncompetitive inhibition in an Acyl-CoA chain length-dependent manner. J Biol Chem 284: 16090-16098, 2009.

80. Dawson G and Qin J: Gilenya (FTY720) inhibits acid sphingomyelinase by a mechanism similar to tricyclic antidepressants. Biochem Biophys Res Commun 404: 321-323, 2011.

81. Ogretmen B: Sphingolipid metabolism in cancer signalling and therapy. Nat Rev Cancer 18: 33-50, 2018.

82. Hannun YA and Obeid LM: Principles of bioactive lipid signalling: Lessons from sphingolipids. Nat Rev Mol Cell Biol 9: 139-150, 2008.

83. Hannun YA and Obeid LM: Sphingolipids and their metabolism in physiology and disease. Nat Rev Mol Cell Biol 19: 175-191, 2018.

84. Hayashi A, Hong J and Iacobuzio-Donahue CA: The pancreatic cancer genome revisited. Nat Rev Gastroenterol Hepatol 18: 469-481, 2021.

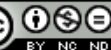

This work is licensed under a Creative Commons Attribution-NonCommercial-NoDerivatives 4.0 International (CC BY-NC-ND 4.0) License. 